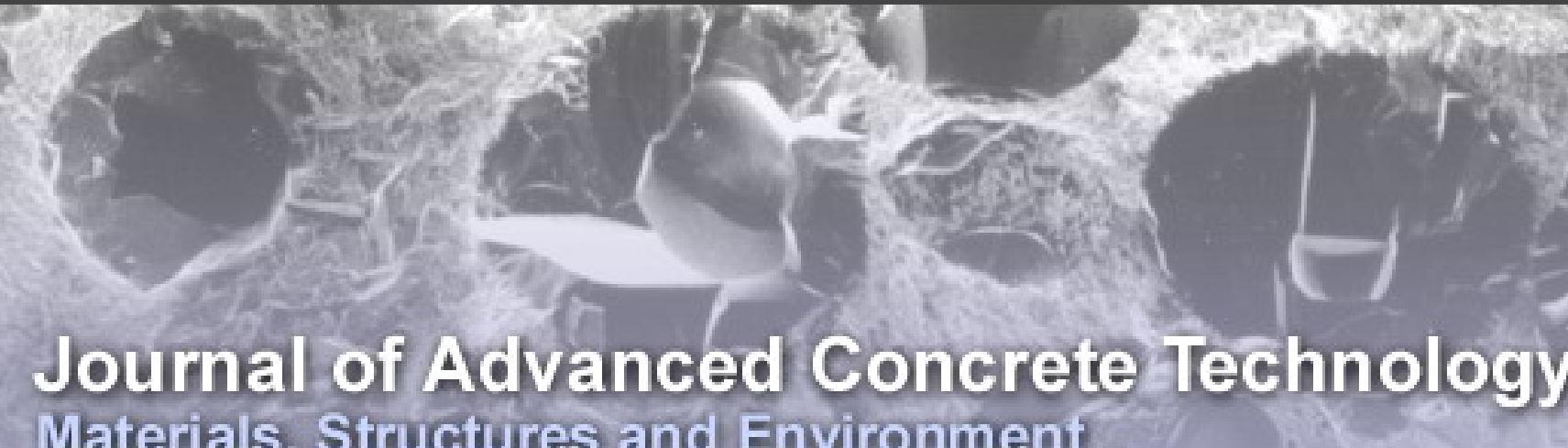

Materials, Structures and Environment

\title{
Compressive Strength and Deformation Capacity of Concrete under Sustained Loading and Low Stress Rates
}

Darko Tasevski, Miguel Fernández Ruiz and Aurelio Muttoni

Journal of Advanced Concrete Technology, volume16 (2018), pp.396-415.

\section{Related Papers Click to Download full PDF!}

Predicting the Creep Strain of PVA-ECC at High Stress Levels based on the

Evolution of Plasticity and Damage

Benny Suryanto, Koichi Maekawa, Kohei Nagai

Journal of Advanced Concrete Technology, volume 11 (2013), pp. 35-48.

Relationship between Nonlinear Creep and Cracking of Concrete under Uniaxial Compression

Miguel Fernández Ruiz, Aurelio Muttoni, Pietro G. Gambarova

Journal of Advanced Concrete Technology, volume 5 (2007), pp. 383-393.

\section{Tensile Creep of High-Strength Concrete}

Hans-Wolf Reinhardt, Tassilo Rinder

Journal of Advanced Concrete Technology, volume 4 (2006), pp. 277-283.

Time-Dependent Nonlinearity of Compression Softening in Concrete

Khaled Farouk El-Kashif, Koichi Maekawa

Journal of Advanced Concrete Technology, volume 2 (2004), pp. 233-247.

Cyclic Cumulative Damaging of Reinforced Concrete in Post-Peak Regions Koichi Maekawa, Khaled Farouk El-Kashif

Journal of Advanced Concrete Technology, volume 2 (2004), pp. 257-271

\section{Click to Submit your Papers}




\title{
Scientific paper
}

\section{Compressive Strength and Deformation Capacity of Concrete under Sustained Loading and Low Stress Rates}

\author{
Darko Tasevski $^{1 *}$, Miguel Fernández Ruiz ${ }^{2}$ and Aurelio Muttoni ${ }^{3}$
}

\begin{abstract}
This paper investigates the behaviour of concrete failing under high stress levels and subjected to different types of loading. The aim of this investigation is to clarify the development of linear and nonlinear creep strains and how they relate to material damage and eventual failure. This research is supported on the results of a new experimental programme performed on concrete cylinders tested in uniaxial compression under varying strain and stress rates. The results of this programme allow investigating the influence of the loading history on the material response in terms both of its strength and deformation capacity. On this basis, a failure criterion related to the inelastic strain capacity of concrete is defined. Such failure criterion, showing consistent agreement for all types of loading histories, allows calculating in a simple manner the reduction of the strength for a long-term loading situation and also its associated deformation capacity. On that basis, a comprehensive method for predicting failure of concrete under different long-term loading patterns is proposed and validated.
\end{abstract}

\section{Introduction}

Many concrete structures are subjected to significant sustained loads over large periods during their lifetime. This is for example the case of large bridges, cut-andcover tunnels (Fig. 1a) and soil-retaining structures. Others are designed to carry mostly rapid load actions typically associated to traffic loads (as underpasses (Fig. 1b) and small bridges), wind or earthquakes.

In the last decades, large research efforts have been dedicated to understand the influence of the load type (sustained, variable) on the behaviour of concrete structures. The influence of sustained loads on the timedependent deformation of structures in the serviceability state has also been widely researched. However, the influence of high levels of stress but variable with time and its structural consequences (stress redistributions for instance) is still poorly investigated and understood.

The phenomenon of creep has traditionally been related to serviceability limit states and hence it has been mostly studied in the elastic domain of response of concrete, normally assumed to be up to about $40 \%$ of its short term resistance. The first studies on compressive creep behaviour above this threshold (Davis 1928; Troxell et al. 1958) were still performed for moderate stress levels (up to $50 \%$ of the short-term strength of

${ }^{1} \mathrm{PhD}$ candidate, Department of Civil Engineering, Ecole Polytechnique Fédérale de Lausanne, Switzerland. *Corresponding author,

E-mail: darko.tasevski@epfl.ch

${ }^{2}$ Senior lecturer, Department of Civil Engineering, Ecole Polytechnique Fédérale de Lausanne, Switzerland.

${ }^{3}$ Professor, Department of Civil Engineering, Ecole Polytechnique Fédérale de Lausanne, Switzerland. concrete), but already indicated that an amplification of creep strains occurs at high sustained loads ("the creep per unit stress at the higher levels of stress intensity was significantly greater" (Troxell et al. 1958)). With respect to the age of loading, it was observed a lower influence of the level of stress on the creep behaviour for concretes loaded at older ages. Other authors (Freudenthal and Roll 1958; Roll 1964) performed extensive studies of concrete under sustained compressive loads for various concrete mixes, showing that the strength increase with age depended also on the specimen geometry (influencing the drying conditions). They also concluded that there is in general an increase of strength for specimens subjected to sustained loading. However, it is important to mention that their specimens were loaded with sustained stress levels up to $60 \%$ of
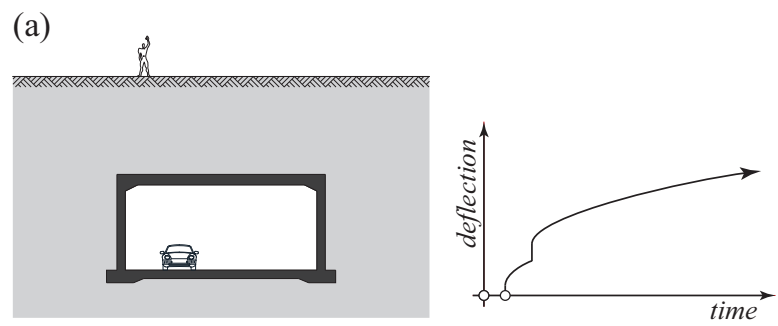

(b)
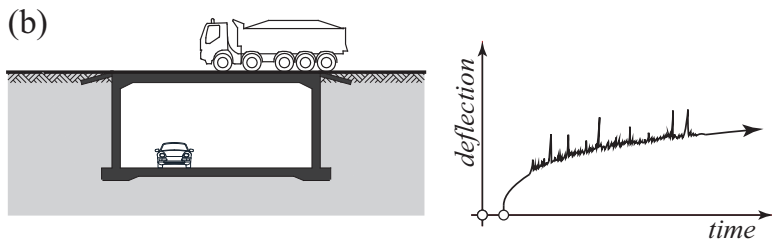

Fig. 1 Influence of sustained and rapid loads on structures: (a) cut-and-cover tunnel under permanent soil load; and (b) underpass under traffic load. 
Table 1 Experimental programmes performed in the scientific literature for failure of concrete in compression under sustained loading.

\begin{tabular}{|c|c|c|c|c|c|c|}
\hline Reference & $\begin{array}{c}f_{c, r e f}\left(t_{0}\right) \\
{[\mathrm{MPa}]}\end{array}$ & $\begin{array}{c}\text { Observed threshol } \\
f_{c, \Delta t} / f_{c, r e f}\left(t_{0}\right) \\
{[-]}\end{array}$ & $\begin{array}{c}t_{0} \\
{[\mathrm{~d}]}\end{array}$ & $\begin{array}{c}\text { Tested } \Delta t \\
\text { up to: } \\
{[-]}\end{array}$ & $\begin{array}{c}\text { Tested } \\
f_{c, \Delta t} / f_{c, r e f}\left(t_{0}\right) \\
{[-]}\end{array}$ & $\begin{array}{c}\text { Failure } \\
\Delta t \\
{[-]} \\
\end{array}$ \\
\hline Sell, 1959 & 32 & 0.70 & 56 & $7 \mathrm{~d}$ & - & - \\
\hline Rüsch, 1960 & $20-60$ & 0.75 & var. & $2 \mathrm{y}$ & $\begin{array}{l}0.75 \\
0.80 \\
0.85 \\
0.90\end{array}$ & $\begin{array}{l}\text { up to } 6 \text { months } \\
\text { up to } 3 \text { months } \\
\text { up to several days } \\
\text { up to several hours }\end{array}$ \\
\hline Awad, 1971 & $16-41$ & - & var. & $4 \mathrm{~d}$ & $\begin{array}{l}0.85 \\
0.90 \\
0.95\end{array}$ & $\begin{array}{l}\text { up to } 4.5 \text { days } \\
\text { up to } 7 \text { hours } \\
\text { up to } 1.5 \text { hours }\end{array}$ \\
\hline Stöckl, 1972 & 50 & 0.80 & 28 & $15 \mathrm{y}$ & $0.70-0.75$ & several failures reported \\
\hline Smadi et al, 1982 & $\begin{array}{l}20-25 \\
35-40 \\
60-70\end{array}$ & $\begin{array}{l}0.75 \\
0.75 \\
0.80\end{array}$ & 28 & $6 \mathrm{~m}$ & $\begin{array}{c}- \\
0.75 \\
0.80\end{array}$ & $\begin{array}{l}2 \text { fail at } 49 \text { days, } 2 \text { no fail } \\
2 \text { fail at } 14 \text { days, } 2 \text { no fail }\end{array}$ \\
\hline Iravani et al, 1998 & $\begin{array}{c}65 \\
95 \\
105 \\
120\end{array}$ & $\begin{array}{l}0.70-0.75^{*} \\
0.75-0.80^{*} \\
0.85-0.90^{*} \\
0.85-0.90^{*}\end{array}$ & 56 & $3 \mathrm{~m}$ & $\begin{array}{l}0.75 / 0.80^{*} \\
- \\
0.90 / 0.95^{*} \\
-\end{array}$ & $\begin{array}{c}\text { fail at } 30 \text { days / } 7 \text { days } \\
\text { fail at } 0.5 \text { days / } 9 \text { min }\end{array}$ \\
\hline
\end{tabular}

the 28-day short term strength, and then loaded rapidly to failure on the day of removing of sustained load.

With respect to very high levels of sustained compressive stress (close to the short-term strength), Shank (Shank 1949) and Rüsch (Rüsch 1956; Rüsch 1960; Rüsch et al. 1968) were amongst the first authors to investigate the existence of a delayed failure under sustained loading. In 1960, Rüsch established the term "sustained load strength" (Rüsch 1960) for the critical stress level leading to failure under sustained loading, which was found to be approximately $75 \%$ of the short term strength. That research work established a failure limit for concrete under sustained load, governing for stress levels above that critical degree of loading (see Fig. 2a). For a sustained load below the critical degree of loading, concrete would on the contrary reach the socalled creep limit (strains increase with time by creep deformations but not leading to failure). This pioneer work was followed by several researchers, some of which have studied the failure under compressive creep of normal strength concrete (Shah and Chandra 1970; Awad and Hilsdorf 1971; Diaz and Hilsdorf 1971; Stöckl 1972; Wittmann and Zaitsev 1974; Coutinho 1977; Fouré 1985; Smadi et al. 1985; Nechvatal et al. 1994; El-Kashif and Maekawa 2004; Maekawa and ElKashif 2004; Fernández Ruiz et al. 2007; Suryanto et al. 2013; Wang et al. 2015; Schlappal et al. 2017) as well as of high strength concrete (Ngab et al. 1981; Smadi 1983; Smadi et al. 1985; Han and Walraven 1994; Müller and Burkart 2010; Anders 2012). Several authors have even provided results on the influence of sustained loads on the multiaxial behaviour and Poisson's ratio (Bažant 1970; Zhaoxia 1994; Benboudjema et al. 2001; Mazzotti and Savoia 2002; Aili et al. 2015).

Table 1 gives an overview of other experimental works on sustained load strength of concrete in compression. In accordance to the findings of Rüsch, most of the researchers have found that failure under sustained load occurs for normal strength concrete at approximately $70 \%$ to $75 \%$ of its short term strength.

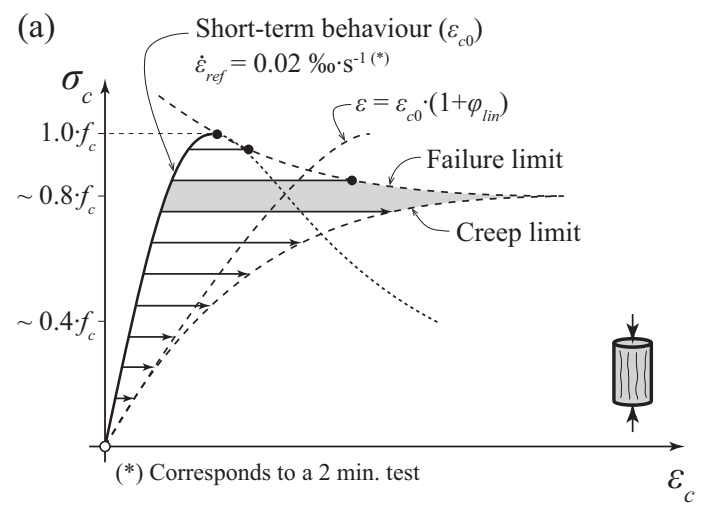

(b)



Fig. 2 Response of concrete under uniaxial compressive stresses: (a) short- and long-term stress-longitudinal strain diagram according to (Rüsch 1960); and (b) evolution of creep strains with time (primary, secondary and tertiary stages of creep). 
Completing these researches, several works have also been performed on the phenomenon of sustained load strength for low compressive loading rates (El-Kashif and Maekawa 2004; Fernández Ruiz et al. 2007; Fischer et al. 2014; Tasevski et al. 2015; Tasevski et al. 2016) as well as for flexural and tensile loading (Domone 1974; Reinhardt and Cornelissen 1985; Zhou 1992; Carpinteri et al. 1997; Rinder 2003; Barpi and Valente 2005; Reinhardt and Rinder 2006; Omar et al. 2009).

Regarding the kinematics of creep strains under high constant stresses, three stages of behaviour can generally be distinguished in the development of creep as mentioned by several authors (Zhou 1992; Berthollet et al. 2004; Bockhold and Stangenberg 2004), namely primary, secondary and tertiary creep (Fig. 2b). The primary creep relates to a kinematics associated to a decreasing rate of strains $(\ddot{\varepsilon}<0)$. The secondary creep is characterized by a roughly constant rate of strains $(\ddot{\varepsilon} \sim 0)$, whereas the tertiary creep is associated to an increasing rate of strains ( $\ddot{\varepsilon}>0$, eventually leading to failure). The development of secondary and tertiary creep strains is highly dependent on the stress level $\left(\sigma_{c} / f_{c}\right)$ to which concrete is subjected. With this respect, several phenomenological discussions can be found in recent literature (Rossi et al. 1994; Bažant and Xiang 1997; Berthollet et al. 2004; Denarié et al. 2006; Fernández Ruiz et al. 2007; Rossi et al. 2012; Rossi et al. 2013). In general, linear creep strains are associated to delayed strains occurring in concrete without material damage (low $\sigma_{c} / f_{c}$ ratios). For higher stress levels, nonlinear creep strains develop due to microcrack initiation and progress in the concrete, implying material damage (Rossi et al. 2013). Under some conditions (high sustained $\sigma_{c} / f_{c}$ ratios, normally above 0.75 ), the tertiary creep stage may develop, characterized by microcrack progression and coalescence (creation of macrocracks), which is accompanied by additional nonlinear creep strains and eventually leads to failure under sustained load.

With respect to codes of practice, the topic of nonlinear creep strains is in some cases explicitly considered as in fib Model Code 2010 (fib 2013) or in Eurocode 2 (CEN 2004), where formulas are provided to estimate the linear and nonlinear creep strains for ratios $\sigma_{c} / f_{c}$ normally lower than 0.6 (prior to the development of tertiary creep strains and failure under sustained load). These codes also account for the reduction of strength due to high sustained loads (ratios $\sigma_{c} / f_{c}>0.75$ according to Fig. 2a), although this effect may often be neglected in the design of new structures as it is potentially compensated by the strength increase with concrete age. Despite these indications, no guidelines are normally provided on how to calculate the strains at failure when tertiary creep develops (necessary to calculate potential stress redistributions and system strength) or on how to evaluate the response of concrete for variable stress levels implying nonlinear creep strains (potentially influencing the final material strength).
Within this frame, the necessity of more comprehensive, consistent and realistic models to consider the long-term response and strength of concrete is gaining importance in the last years. This is justified to a large extent by the assessment of existing structures, where the concrete strength is updated at a concrete age where almost no further strength increase can be expected and high levels of sustained load may occur (even after some years of construction due to additional dead loads originated for instance by refurbishing or addition of new stories in buildings or to placing of new asphalt layers in bridges). To contribute to this topic, this paper presents the results of a comprehensive investigation on the influence of high levels of sustained stresses on the concrete compressive strength and deformation capacity, with particular focus on variable stress histories. The main aim is to provide a general and consistent framework to address the linear and nonlinear creep strains and to calculate the progression of material damage and delayed failure under a general loading history. To that aim, the results of a specific experimental programme are presented and discussed. Finally, the experimental results are analysed by extending a theoretical approach previously developed by the authors (Fernández Ruiz et al. 2007). The model is shown to accurately predict both the strength and the deformation capacity at failure and to allow investigating on the various parameters influencing the phenomenon.

\section{Development of linear and nonlinear creep strains in concrete}

\subsection{Types of time-dependent strains under sus- tained loading}

This section presents a brief summary of the state of knowledge on the uniaxial concrete behaviour under constant sustained loads that will later be extended in this paper. To that aim, creep strains will be considered as the strains developed in time in excess of those associated to shrinkage (Rüsch 1960).

At sustained stress levels lower than approximately $0.4 \cdot f_{c}$, there is an almost linear correlation between the delayed creep strains and the short term strains (Fig. 2a). The behaviour under sustained stress consists in this case of primary creep, where the creep rate is high at the beginning and progressively decreases with time (Fig. 2b). At stress levels higher than approximately $0.4 \cdot f_{c}$, the damage process in the material starts. A part of the damage process occurs during the application of the load (microcrack generation) and another part during the stage of sustained loading (mostly due to microcrack propagation). The linear correlation between the delayed creep strain and the elastic strain is lost and additional nonlinear creep strains develop.

The second threshold (Fig. 2a, shaded area) describes the stress level above which delayed failures are possible. At stress levels higher than $\sim 0.75 \cdot f_{c}$, microcrack coalescence may develop giving rise to the onset of the 
tertiary creep phase. This phase is characterized by an increasing rate of delayed deformations, with a final uncontrolled process of progressive crack coalescence leading to failure (stage III in Fig. 2b). It is worth noting that the value of the second threshold may vary between $0.75-0.80$ for normal strength concrete and $0.80-0.85$ for high strength concrete, according to the literature reported in Table 1.

\subsection{Failure under sustained load - inelastic strain capacity}

As already well established for rocks (Goodman 1989), failure as a result of creep in compression can be predicted based on the stress-strain curve. According to Goodman (Goodman 1989), for high levels of sustained stress, the creep process leads to failure if the accumulated inelastic strain developed within the creep process intersects the descending branch of the stress-strain curve. With respect to concrete, many authors (see for instance (Karsan and Jirsa 1969; Zhou 1992)) have also used the monotonic stress-strain curve of concrete as a failure criterion in the case of cyclic loading.

Consistently with these observations, and following the approach of (Fernández Ruiz et al. 2007), it can be assumed that the inelastic strain capacity for a given stress level is equal to the difference between the instantaneous post- and pre-peak strains for that level of stress, see Fig. 3a. This value can thus be directly calculated by using the monotonic stress-strain curve of concrete in compression, refer to Figs. $\mathbf{3 a}$ and $\mathbf{3 b}$ where a reference strain rate $\dot{\varepsilon}=0.02 \% \mathrm{os}^{-1}$ is usually considered to characterize the monotonic response (approximately 100 seconds to reach the maximum strength). This approach has shown to yield consistent results (Fernández Ruiz et al. 2007) and its validity will later be investigated and confirmed by the results presented in this paper.

The inelastic strain developed within a process of sustained loading can on the other hand be calculated by removing the pre-peak instantaneous strain, the shrinkage strains and the linear creep strains from the total measured strain. If the stress level in a sustained load test is high enough $\left(\sigma_{c} / f_{c} \geq 0.75\right)$, the inelastic strains developed in the concrete may reach the strain capacity and failure occurs, refer to Fig. 3c. Otherwise, for moderate or low levels of stress, the inelastic strain capacity is not attained (creep limit, Fig. 3c). In such case, the load in the specimen can still be increased until failure (Fernández Ruiz et al. 2007).

\subsection{Analysis of creep effects based on the affin- ity assumption between linear and nonlinear (secondary) creep strains}

Fernández Ruiz et al. presented in a previous work (Fernández Ruiz et al. 2007) a framework for predicting the nonlinear creep strains of concrete under high levels of sustained stress. That method was originally developed only for constant sustained loads. The approach was based on the assumption that the strains developed over time $t$ in a concrete structure loaded at time $t_{0}$ can be described by following expression:

$$
\varepsilon_{c}\left(t, \frac{\sigma_{c}}{f_{c}}\right)=\varepsilon_{c 0}\left(t_{0}, \frac{\sigma_{c}}{f_{c}}\right)+\Delta \varepsilon_{c s}\left(t, t_{0}\right)+\Delta \varepsilon_{c c}\left(t, t_{0}, \frac{\sigma_{c}}{f_{c}}\right)
$$

where the first term on the right side of the equation ( $\varepsilon_{c}\left(t_{0}, \frac{\sigma_{c}}{f_{c}}\right)$ ) corresponds to the instantaneous pre-peak strain (including elastic and inelastic components), the second $\left(\Delta \varepsilon_{c s}\left(t, t_{0}\right)\right)$ to the shrinkage strains and the third $\left(\Delta \varepsilon_{c c}\left(t, t_{0}, \frac{\sigma_{c}}{f_{c}}\right)\right)$ to the creep strains.

The shrinkage strains are considered (according to their definition) to be independent from the material stress state. The creep strains, on their turn, are related to the pre-peak strains by means of a creep coefficient $\varphi$ which depends on the time at loading, the duration of the action and the level of stress:

$$
\Delta \varepsilon_{c c}\left(t, t_{0}, \frac{\sigma_{c}}{f_{c}}\right)=\varepsilon_{c 0}\left(t_{0}, \frac{\sigma_{c}}{f_{c}}\right) \cdot \varphi\left(t, t_{0}, \frac{\sigma_{c}}{f_{c}}\right)
$$

The creep coefficient can be assumed to be stress independent for sustained stress levels below $0.4 \cdot f_{c}$ $\left(\varphi=\varphi_{\text {lin }}\left(t, t_{0}\right)\right)$. Above this threshold, the creep coeffi- (a)

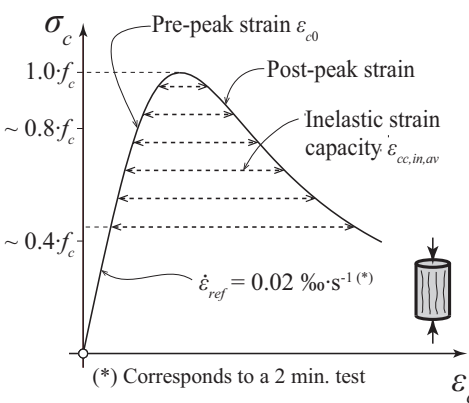

(b)

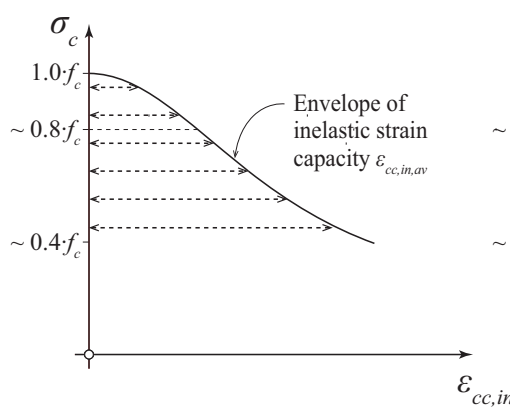

(c)

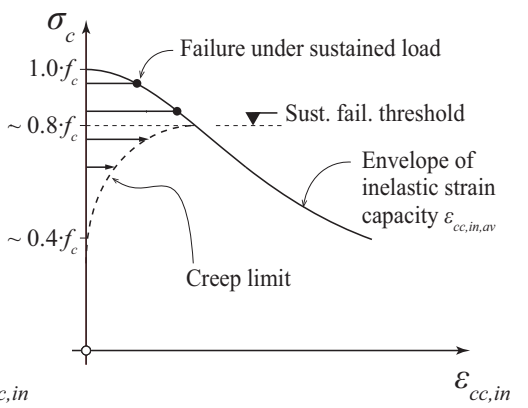

Fig. 3 Inelastic strain capacity: (a) instantaneous pre- and post-peak longitudinal strains; (b) definition of the inelastic strain capacity as difference between instantaneous post- and pre-peak longitudinal strains; and (c) failure limit and creep limit. 
cient is no longer stress independent. For its calculation, for stress levels $\sigma_{c} / f_{c}$ below 0.7 (i.e. where no failure under sustained loading occurs), a simple formula was proposed by (Fernández Ruiz et al. 2007) assuming perfect affinity between linear and nonlinear creep strains:

$$
\varphi_{n l}\left(t, t_{0}, \frac{\sigma_{c}}{f_{c}}\right)=\eta\left(\frac{\sigma_{c}}{f_{c}}\right) \cdot \varphi_{l i n}\left(t, t_{0}\right)
$$

where, for design purposes, the coefficient $\eta\left(\sigma_{c} / f_{c}\right)$ can be estimated as (Fernández Ruiz et al. 2007):

$$
\eta\left(\frac{\sigma_{c}}{f_{c}}\right)=1+2\left(\frac{\sigma_{c}}{f_{c}}\right)^{4}
$$

The validity of Eq. (4) was demonstrated at long-term and for stress levels $\sigma_{c} / f_{c}<0.7$, showing a satisfactory agreement to test results (Fernández Ruiz et al. 2007). Beyond the threshold of validity of Eq. (4) (stress levels $\sigma_{c} / f_{c}$ above 0.7 , where tertiary creep strains potentially develop), Fernández Ruiz et al. proposed, based on existing experimental data, that the total inelastic strain at sustained load failure is roughly composed by $2 / 3$ of the nonlinear strain according to Eq. (4) and $1 / 3$ of additional strains due to tertiary creep (Fernández Ruiz et al. 2007). These considerations will later be discussed more in detail in this paper.

After publication of that work (Fernández Ruiz et al. 2007), the authors found a similar approach to that of Eq. (4) in the old USSR code of practice (USSR 1987) based on the following expression (original notation modified to be consistent to the one of this paper):

$$
\eta\left(\frac{\sigma_{c}}{f_{c}}\right)=1+V_{t}\left(\frac{\sigma_{c}}{f_{c}}\right)^{m}
$$

where $V_{t}=V_{0} \cdot e^{-f}$ and $f=f\left(t-t_{0}\right)=k \cdot e^{-\gamma \cdot(t-t 0)}$. The values of $V_{0}, k, \gamma$ and $m$ are given in the USSR code for different strength classes of normal hardening concrete, but do not differ much from those of Eq. (4). It is interesting to note that the approach is very similar, and yields comparable results which confirm the plausibility (and practical interest) of the approach.

In this article, the validity of the affinity hypothesis for the entire progress of tertiary creep development is examined, and a generalization for different load cases is proposed.

\section{Experimental programme}

The aim of this experimental programme is to study the response of normal strength concrete at high stress levels both at varying strain and stress rates.

\subsection{Materials and testing methods}

The uniaxial compressive behaviour of concrete under different strain and stress rates has been investigated by means of cylindrical specimens with dimensions $\varnothing \times h=160 \times 320 \mathrm{~mm}$. The concrete was produced with a CEM-II $42.5 \mathrm{R}$ cement $(\mathrm{w} / \mathrm{c}=0.56)$ and Rhone river aggregates. The specimens were kept moulded (with the top face sealed) until the age of 21 days. Thereafter, the specimens were unmoulded and stored under standard laboratory conditions (temperature of $21^{\circ} \mathrm{C}$ and relative humidity of $65 \%$ ) until testing. The tests were performed using a Schenck Hydroplus servohydraulic testing machine (Fig. 4a) with capacity of 2.5 MN and a custom-made steel frame which enhances the stiffness of the test setup (Fernández Ruiz et al. 2007). The climatic room where the tests were performed has controlled temperature $\left(21 \pm 0.5^{\circ} \mathrm{C}\right)$ and relative humidity $(65 \pm 3 \%$, some minor deviations are commented later). The longitudinal strain of the specimens $\varepsilon_{c, \text { long }}$ was measured with three surface displacement transducers (omega gauges) arranged radially on two steel rings at a distance of $250 \mathrm{~mm}$ (see Fig. 4b). The signal of the three transducers was acquired at high frequency $(1200 \mathrm{~Hz})$ and it was used to control the strain rate (in the strain rate test series) directly on the specimen. The transverse strain $\varepsilon_{c \text {,trans }}$ was measured with a steel ribbon dilatometer (Fig. 4b) equipped with a linear variable differential transformer (LVDT).

The reference compressive strength was tested at a strain rate of $0.02 \% \mathrm{o}^{-1}$, corresponding to approximately 100 seconds before maximum strength is reached. Its development with concrete age has been compared to the Model Code 2010 (fib 2013) formula:

$$
f_{c, r e f}\left(t_{0}\right)=f_{c, 28} \cdot e^{s \cdot\left[1-\sqrt{\frac{28}{t}}\right]}
$$

where $f_{c, 28}=29.0 \mathrm{MPa}$ and $t$ refers to the concrete age in days. The coefficient $s$ was adapted by means of least square fitting and returns the value $s=0.316$. The resulting development curve is given in Fig. 5a.

With respect to the shrinkage strains, a shrinkage rig with three cylindrical specimens was installed after unmoulding of the specimens (at 21 days), see Fig. 4c. The shrinkage measurements were performed during two years. Then, the standard shrinkage model from Model Code 2010 was used to reproduce the measured shrinkage strains (with $\alpha_{a s}=600, \alpha_{d s 1}=6$ and $\alpha_{d s 2}=0.012$ corresponding to a cement class $42.5 \mathrm{R}$ ). The resulting expression is compared in Fig. $\mathbf{5 b}$ to the test results:

$$
\varepsilon_{c s}\left(t, t_{s}\right)=-36.4 \cdot 10^{-6} \cdot\left(1-e^{-0.2 \sqrt{t}}\right)-699 \cdot 10^{-6} \cdot \frac{1}{\sqrt{\frac{224}{t-t_{s}}+1}}
$$

where $t_{s}$ is the concrete age at demoulding in days. Measurements on linear creep were also performed during two years in a standard creep rig with three cylindrical specimens loaded at a stress level $\sigma_{c} / f_{c} \approx 0.35$ at an age of 28 days (Fig. 4d). The creep strains were calculated by removing from the increase of strains with time the value corresponding to the measured shrinkage strains. Then, the standard creep law from Model Code 
2010 was adapted by fitting the parameters to reproduce the measured curve (Fig. 5c):

$$
\varphi\left(t, t_{0}\right)=3.24 \cdot \frac{1}{0.1+t_{0}^{0.2}} \cdot\left[\frac{t-t_{0}}{682+t-t_{0}}\right]^{\frac{1}{2.3+\frac{3.5}{\sqrt{t_{0}}}}}+3.00 \cdot \frac{1}{0.1+t_{0}^{0.2}} \cdot\left[\frac{t-t_{0}}{395+t-t_{0}}\right]^{\frac{1}{2.3+\frac{3.5}{\sqrt{t_{0}}}}}
$$

where $t_{0}$ is the age of concrete at loading. It can be noted that the results obtained with the Model Code 2010 formulae slightly underestimate the linear creep strains and slightly overestimate the shrinkage strains up to the age of approximately 400 days, being fairly accurate thereafter. In any case, the delayed strains (linear creep and shrinkage) are reasonably well estimated by this model. The linear creep law for other loading ages was also calculated according to the Model Code 2010 ex- pression for the creep coefficient (the two grey lines in Fig. 5c represent the calculated linear creep coefficients for the average loading ages of the two experimental series).

It shall be commented that the relative humidity was kept as constant as possible. However, there have been some variations $( \pm 10 \%)$ over very limited periods of time during the two years, mainly due to maintenance operations of the climate regulation system. These variations have been taken into account for the shrinkage and linear creep calculations presented in Fig. 5b and Fig. 5c according to Model Code 2010.

\subsection{Types of loading}

The delayed behaviour of concrete under uniaxial compression has so far been usually investigated with clas-
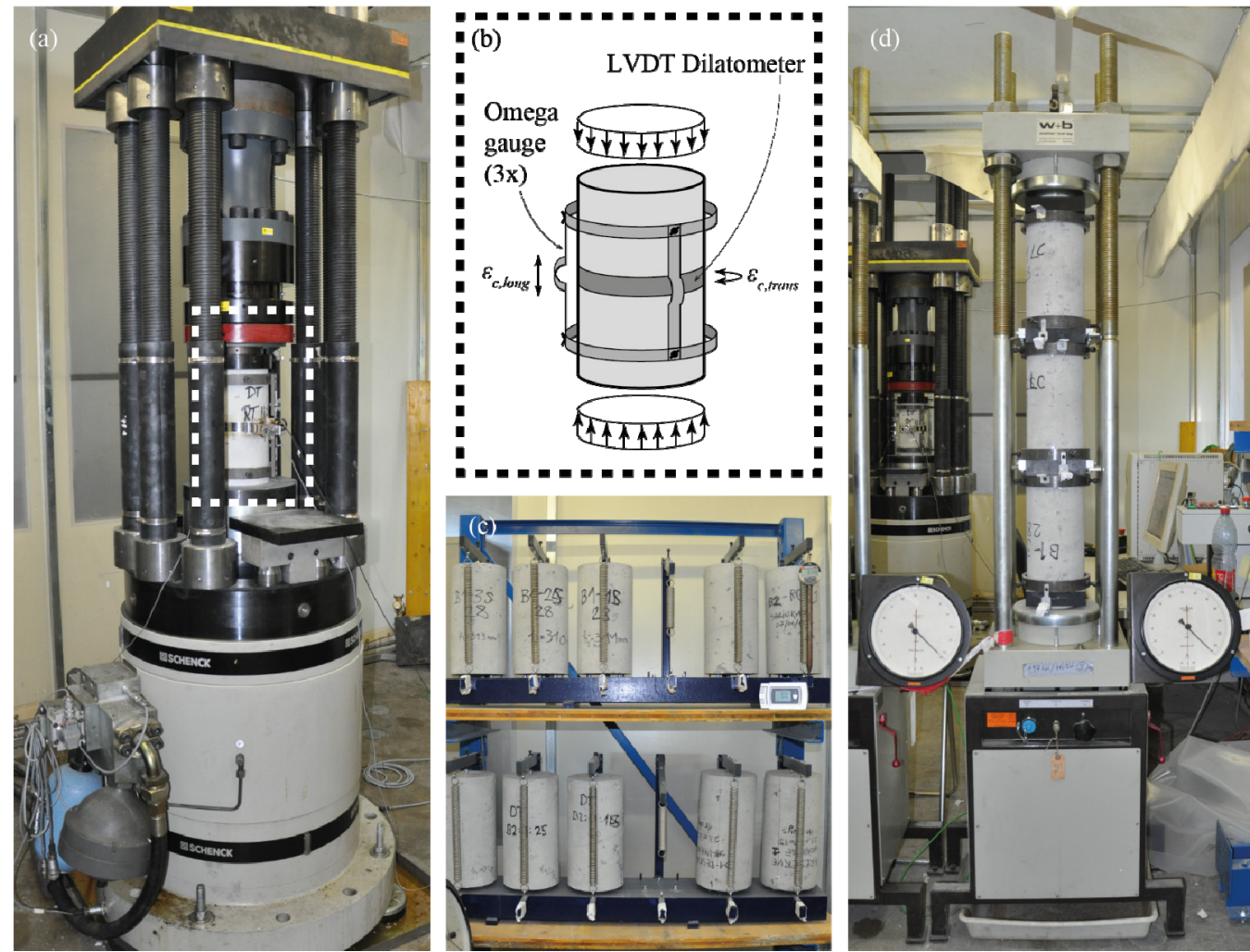

Fig. 4 Test setup: (a) testing frame for stress and strain rate long-term testing; (b) details of measurement devices; (c) shrinkage rigs; and (d) linear creep rigs.

(a)

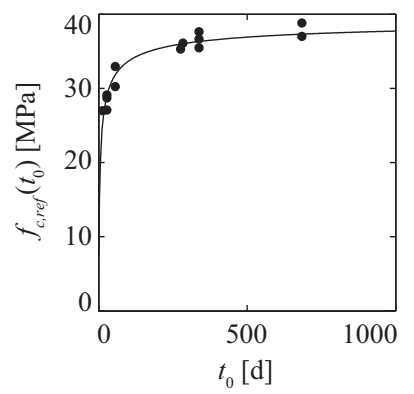

(b)

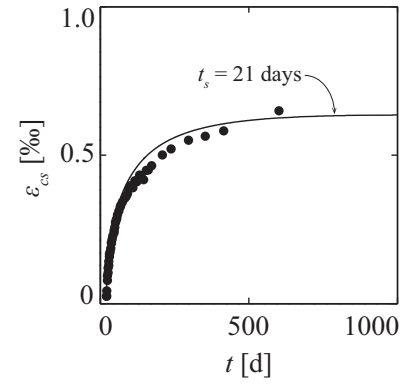

(c)

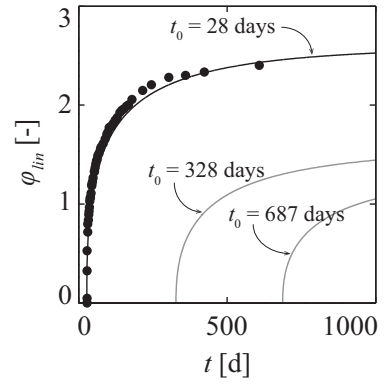

Fig. 5 Time-dependent concrete properties: (a) development of compressive strength with time (tests performed at reference loading rate), (b) longitudinal shrinkage strains and (c) longitudinal linear creep strains $\left(\sigma / f_{c} \approx 0.35\right)$. 
Table 2 Overview of the results of the $1^{\text {st }}$ test series performed with varying strain rate. (rows marked in bold as "Avg." indicating average of specimens with same loading rate)

\begin{tabular}{|c|c|c|c|c|c|c|c|c|}
\hline Test Name & $\begin{array}{c}\dot{\varepsilon} \\
{\left[\mathrm{s}^{-1}\right]}\end{array}$ & $\begin{array}{c}t_{0} \\
{[\mathrm{~d}]}\end{array}$ & $\begin{array}{c}f_{c, r e f}\left(t_{0}\right) \\
{[\mathrm{MPa}]}\end{array}$ & $\begin{array}{l}\Delta t \\
{[\mathrm{~s}]}\end{array}$ & $\begin{array}{c}f_{c, \Delta t} \\
{[\mathrm{MPa}]}\end{array}$ & $\begin{array}{c}f_{c, \Delta t} / f_{c, r e f}\left(t_{0}\right) \\
{[-]}\end{array}$ & $\begin{array}{c}\varepsilon_{c, \text { long }} \\
{[\% 0]} \\
\end{array}$ & $\begin{array}{c}\varepsilon_{c, \text { trans }} \\
{[\% 0]}\end{array}$ \\
\hline DR1_1 & 2.00E-03 & 340 & 36.3 & $1.00 \mathrm{E}+00$ & 40.1 & 1.10 & 2.16 & 0.548 \\
\hline DR2_1 & $2.00 \mathrm{E}-04$ & 340 & 36.3 & $9.20 \mathrm{E}+00$ & 37.9 & 1.04 & 2.21 & 0.562 \\
\hline $\mathrm{DR} 2{ }_{-}^{-} 1$ & $2.00 \mathrm{E}-04$ & 340 & 36.3 & $9.40 \mathrm{E}+00$ & 38.6 & 1.06 & 2.29 & 0.440 \\
\hline Avg. DR2 & 2.00E-04 & 340 & 36.3 & $9.30 \mathrm{E}+00$ & 38.3 & 1.05 & 2.25 & 0.501 \\
\hline DR3_1 (ref.) & $2.00 \mathrm{E}-05$ & 339 & 36.3 & $9.40 \mathrm{E}+01$ & 36.7 & 1.01 & 2.28 & 0.543 \\
\hline DR3 2 (ref.) & $2.00 \mathrm{E}-05$ & 339 & 36.3 & $9.78 \mathrm{E}+01$ & 35.5 & 0.977 & 2.38 & 0.763 \\
\hline DR3_3 (ref.) & $2.00 \mathrm{E}-05$ & 339 & 36.3 & $9.74 \mathrm{E}+01$ & 37.7 & 1.04 & 2.37 & 0.608 \\
\hline Avg. DR3 & 2.00E-05 & 339 & 36.3 & $9.64 E+01$ & 36.6 & 1.01 & 2.34 & 0.638 \\
\hline DR4_1 & $2.00 \mathrm{E}-06$ & 284 & 36.0 & $1.02 \mathrm{E}+03$ & 33.8 & 0.939 & 2.49 & 0.726 \\
\hline DR4_2 & $2.00 \mathrm{E}-06$ & 280 & 36.0 & $1.09 \mathrm{E}+03$ & 35.9 & 0.999 & 2.62 & 0.998 \\
\hline Avg. DR4 & 2.00E-06 & 282 & 36.0 & $1.06 \mathrm{E}+03$ & 34.9 & 0.969 & 2.56 & 0.862 \\
\hline DR5_1 & $2.00 \mathrm{E}-07$ & 276 & 36.0 & $1.16 \mathrm{E}+04$ & 34.7 & 0.966 & 2.81 & 0.813 \\
\hline DR5 5 & $2.00 \mathrm{E}-07$ & 278 & 36.0 & $1.21 \mathrm{E}+04$ & 34.5 & 0.959 & 2.95 & 1.34 \\
\hline Avg. DR5 & 2.00E-07 & 277 & 36.0 & $1.19 E+04$ & 34.6 & 0.962 & 2.88 & 1.08 \\
\hline DR6 1 & $2.00 \mathrm{E}-08$ & 343 & 36.3 & $1.26 \mathrm{E}+05$ & 34.1 & 0.939 & 3.09 & 0.956 \\
\hline DR7_1 & $2.00 \mathrm{E}-09$ & 440 & 36.7 & $1.21 \mathrm{E}+06$ & 34.2 & 0.932 & 2.94 & 0.396 \\
\hline
\end{tabular}

Table 3 Overview of the results of the $2^{\text {nd }}$ test series performed with varying stress rate. (rows marked in bold as "Avg." indicating average of specimens with same loading rate)

\begin{tabular}{|c|c|c|c|c|c|c|c|c|}
\hline Test Name & $\begin{array}{c}\dot{\sigma} \\
{\left[\mathrm{MPa} \cdot \mathrm{s}^{-1}\right]}\end{array}$ & $\begin{array}{c}t_{0} \\
{[\mathrm{~d}]}\end{array}$ & $\begin{array}{c}f_{c, r e f}\left(t_{0}\right) \\
{[\mathrm{MPa}]}\end{array}$ & $\begin{array}{l}\Delta t \\
{[\mathrm{~s}]}\end{array}$ & $\begin{array}{c}f_{c, \Delta t} \\
{[\mathrm{MPa}]}\end{array}$ & $\begin{array}{c}f_{c, \Delta t} / f_{c, r e f}\left(t_{0}\right) \\
{[-]}\end{array}$ & $\begin{array}{c}\varepsilon_{c, \text { long }} \\
{[\% 0]}\end{array}$ & $\begin{array}{c}\varepsilon_{c, \text { trans }} \\
{[\% 0]}\end{array}$ \\
\hline LRO 1 & $5.00 \mathrm{E}+00$ & 728 & 37.4 & $5.00 \mathrm{E}-01$ & 38.9 & 1.04 & 2.27 & - \\
\hline LR1 1 & $5.00 \mathrm{E}-01$ & 684 & 37.3 & $3.19 \mathrm{E}+01$ & 39.8 & 1.07 & 2.36 & 0.918 \\
\hline LR1_2 & $5.00 \mathrm{E}-01$ & 684 & 37.3 & $2.89 \mathrm{E}+01$ & 38.8 & 1.04 & 2.53 & 0.984 \\
\hline LR1_3 & $5.00 \mathrm{E}-01$ & 684 & 37.3 & $2.39 \mathrm{E}+01$ & 37.0 & 0.992 & 2.52 & 1.08 \\
\hline Avg. LR1 & $5.00 \mathrm{E}-01$ & 684 & 37.3 & $2.82 \mathrm{E}+01$ & 38.5 & 1.03 & 2.47 & 0.994 \\
\hline LR2_1 & $5.00 \mathrm{E}-02$ & 678 & 37.3 & $1.27 \mathrm{E}+02$ & 35.3 & 0.948 & 2.72 & 1.69 \\
\hline LR2_2 & $5.00 \mathrm{E}-02$ & 679 & 37.3 & $2.28 \mathrm{E}+02$ & 40.0 & 1.07 & 2.69 & 1.19 \\
\hline LR2_3 & $5.00 \mathrm{E}-02$ & 679 & 37.3 & $1.87 \mathrm{E}+02$ & 38.1 & 1.02 & 2.67 & 1.40 \\
\hline Avg. LR2 & $5.00 \mathrm{E}-02$ & 679 & 37.3 & $1.81 \mathrm{E}+02$ & 37.8 & 1.01 & 2.69 & 1.43 \\
\hline LR3_1 & $5.00 \mathrm{E}-03$ & 678 & 37.3 & $1.38 \mathrm{E}+03$ & 35.6 & 0.954 & 2.96 & 1.46 \\
\hline LR3_2 & $5.00 \mathrm{E}-03$ & 682 & 37.3 & $1.71 \mathrm{E}+03$ & 37.3 & 1.00 & 2.85 & 1.75 \\
\hline LR3 3 & $5.00 \mathrm{E}-03$ & 682 & 37.3 & $1.53 E+03$ & 36.1 & 0.968 & 2.99 & 2.21 \\
\hline Avg. LR3 & $5.00 \mathrm{E}-03$ & 682 & 37.3 & $1.54 \mathrm{E}+03$ & 36.4 & 0.974 & 2.93 & 1.81 \\
\hline LR4 1 & $1.50 \mathrm{E}-03$ & 650 & 37.2 & $4.08 E+03$ & 34.7 & 0.933 & 2.94 & 2.27 \\
\hline LR5 1 & $5.00 \mathrm{E}-04$ & 682 & 37.3 & $1.33 \mathrm{E}+04$ & 35.4 & 0.949 & 2.90 & 1.88 \\
\hline LR5_2 & $5.00 \mathrm{E}-04$ & 683 & 37.3 & $1.60 \mathrm{E}+04$ & 36.6 & 0.981 & 3.41 & 2.02 \\
\hline Avg. LR5 & $5.00 \mathrm{E}-04$ & 683 & 37.3 & $1.47 \mathrm{E}+04$ & 36.1 & 0.965 & 3.16 & 1.95 \\
\hline LR6_1 & $5.00 \mathrm{E}-05$ & 684 & 37.3 & $1.43 \mathrm{E}+05$ & 36.4 & 0.977 & 3.60 & 2.06 \\
\hline LR6_2 & $5.00 \mathrm{E}-05$ & 707 & 37.3 & $1.82 \mathrm{E}+05$ & 37.6 & 1.01 & 2.95 & 1.05 \\
\hline Avg. LR6 & $5.00 \mathrm{E}-05$ & 696 & 37.3 & $1.63 E+05$ & 37.0 & 0.992 & 3.28 & 1.56 \\
\hline LR7 1 & $1.25 \mathrm{E}-05$ & 742 & 37.4 & $4.48 \mathrm{E}+05$ & 34.2 & 0.914 & 3.28 & 1.35 \\
\hline
\end{tabular}

sical creep tests where a constant stress level is sustained over time (Rüsch 1960; Fernández Ruiz et al. 2007). To investigate other long-term loading patterns, two new test series were performed in this study.

The first test series was performed by varying the strain rate (see Fig. 6). To have a fairly mature concrete and to limit the influence of strength increase with time, the concrete age at testing varied between 10 and 14 months (for more details on the evolution of concrete strength with time refer to Fig. 5a and Table 2). This test series covered strain rates ranging from $2.00 \cdot 10^{-3} \mathrm{~s}^{-1}$ to $2.00 \cdot 10^{-9} \mathrm{~s}^{-1}$ (time to failure from 1 second to ca. 14 days).

The second test series of uniaxial compression was performed by varying the stress rate. The concrete age at testing varied between 22 and 24 months (refer again to Fig. 5a and Table 3). First, an initial loading ramp $\left(3.50 \cdot 10^{-1} \mathrm{MPa} \cdot \mathrm{s}^{-1}\right)$ was applied up to $80 \%$ of the reference strength $\left(\dot{\varepsilon}=0.02 \%{ }^{-1}\right.$ ) at the day of loading (see Fig. 7). Then, a second loading ramp was applied from $5.00 \cdot 10^{0} \mathrm{MPa} \cdot \mathrm{s}^{-1}$ to $1.25 \cdot 10^{-5} \mathrm{MPa} \cdot \mathrm{s}^{-1}$ (time to failure from 1 second to ca. 5 days).

Despite the fact that the test series of this programme were aimed at investigating the influence of low stress and strain rates on the compressive strength of concrete, some tests with relatively high stress and strain rates were also conducted (tests DR1, DR2 and LR0). The results of these tests are presented in the following, but 
they will not be investigated in detail thereafter.

\subsection{Results for strain rate tests $\left(1^{\text {st }}\right.$ test series)}

Table 2 presents an overview of the results of the test series performed with varying strain rate. The second column indicates the control strain rate, the third and fourth column give the age of concrete and the reference

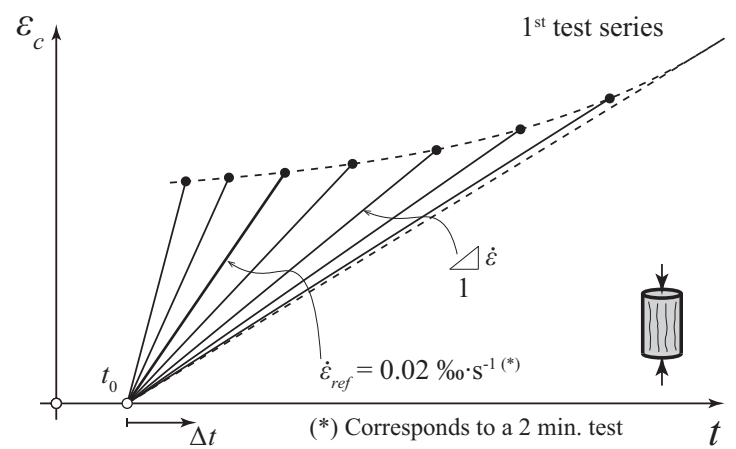

Fig. 6 Loading paths of $1^{\text {st }}$ test series (DR tests): varying longitudinal strain rate.

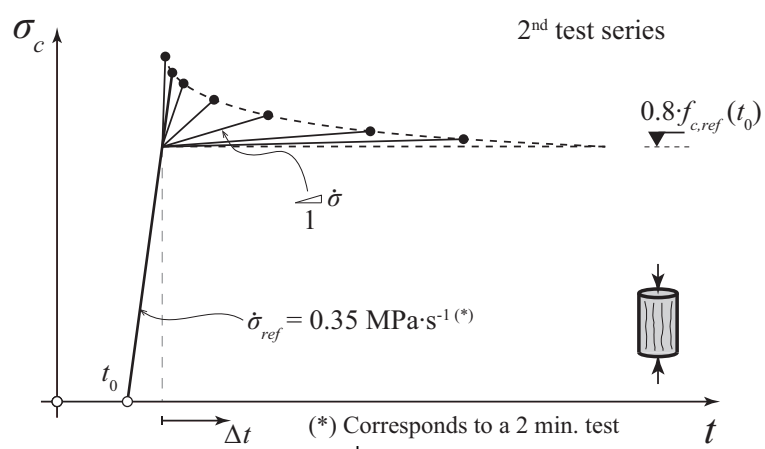

Fig. 7 Loading paths of $2^{\text {nd }}$ test series (LR tests): varying stress rates at hiah stress levels. strength at load application respectively, and columns 5 - 9 give the main results (the average of every strain rate is written in bold font). The stress-strain diagrams are presented and compared to the reference test with $\dot{\varepsilon}=0.02 \%{ }^{-1} \mathrm{~s}^{-1}$ in Fig. 8. The evolution of the stress and of the strains versus time in logarithmic scale is also presented in Figs. 9a - 9c. It is worth noting that the specimen DR7 1 was tested with a very low strain rate and thus a preload had to be applied in order not to lose contact between the specimen and the loading plate (this explains the shape for stresses lower than $0.2 \cdot f_{c, \text { ref }}\left(t_{0}\right)$ in Fig. 9).

These tests confirm that the failure load is lower as the strain rate decreases (load applied over longer periods of time), with a variation of the measured strength to the reference strength (standard loading speed) at the same age ranging from 1.10 (high strain rates) to 0.932 (low strain rates). Also, it can be observed that the longitudinal and transverse strains at failure usually increase with decreasing strain rates. In terms of effective Poisson's ratio $\left(v_{\text {eff }}=\varepsilon_{c, \text { trans }} / \varepsilon_{c, \text { long }}\right.$ ), an increasing trend could be observed with average values from 0.223 for higher strain rates (standard value for concrete tested in displacement control) up to 0.375 for the lower strain rates.

\subsection{Results for stress rate tests $\left(2^{\text {nd }}\right.$ test series)}

Table 3 presents an overview of the results of the test series performed with varying stress rate. The second column indicates the control stress rate after the initial loading ramp, the third and fourth column give the age of concrete and the reference strength at load application respectively, and columns 5 - 9 give the main results (the average of every stress rate is written in bold font). The stress-strain diagrams are presented and

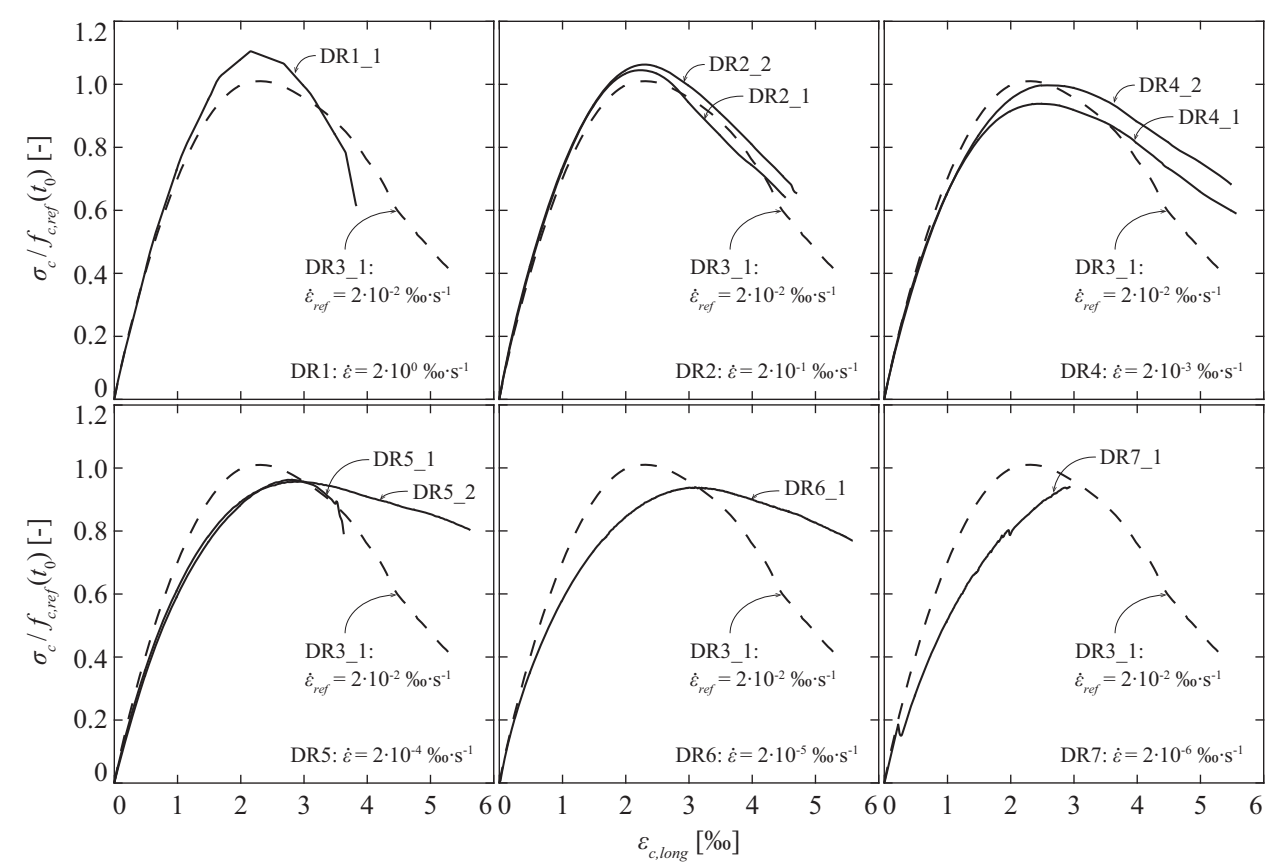

Fig. 8 Stress-strain diagrams of the $1^{\text {st }}$ test series (tests with varying strain rate, refer to Table 2). 


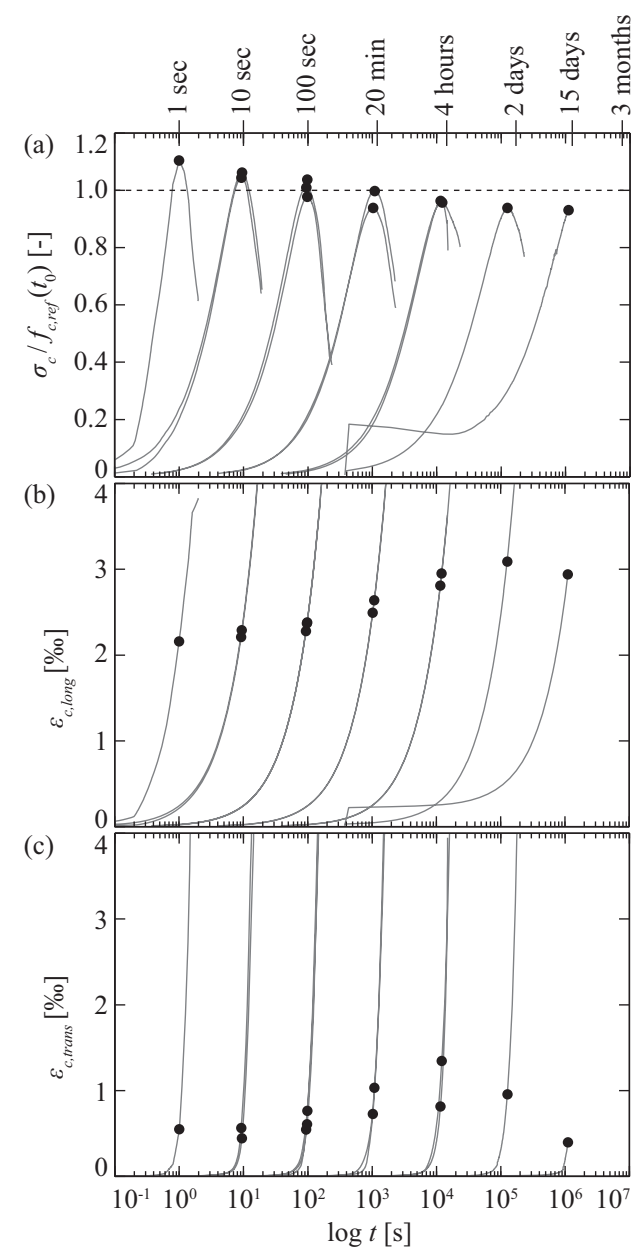

Fig. 9 Results of the $1^{\text {st }}$ test series (tests with varying strain rate): (a) longitudinal stress; (b) longitudinal strain; and (c) transverse strain versus time. compared to the reference test with $\dot{\varepsilon}=0.02 \% \mathrm{~s}^{-1}$ in Fig. 10. The evolution of the stress or the strains versus time in logarithmic scale is additionally presented in Figs. 11a - 11c.

As for the $1^{\text {st }}$ series, it can be observed that the failure load is lower as the stress rate decreases (corresponding to longer times of application of the load, consistently to the strain rate tests). This decrease of the strength is accompanied by larger strains at failure in the longitudinal and transverse directions. Some fluctuations in the results can be observed, probably related to the load control of the test, where the failure occurs in a brittle manner and with no post-peak branch.

In terms of the influence of the stress rate in the measured compressive strength of the material, it varies between 1.07 (high stress rates) and 0.914 (low stress rates) when it is normalized by the reference material strength (obtained with a standard loading speed). The effective Poisson's ratio ( $\left.v_{\text {eff }}=\varepsilon_{c, \text { trans }} / \varepsilon_{c, \text { long }}\right)$, varies also from 0.402 for higher stress rates up to 0.617 for lower stress rates. These latter values (load control) are higher than those observed for strain rates (deformation control).

\subsection{Discussion of inelastic strains developed at failure}

(1) Strain rate tests

As described in Section 2.2, it has been observed for tests under constant sustained stress that when the developed nonlinear (inelastic) creep strain equals the inelastic strain capacity of the material for that level of stress, failure occurs ((Fernández Ruiz et al. 2007), refer to Fig. 3c). To evaluate the validity of this failure criterion for the investigated load patterns, the contributions

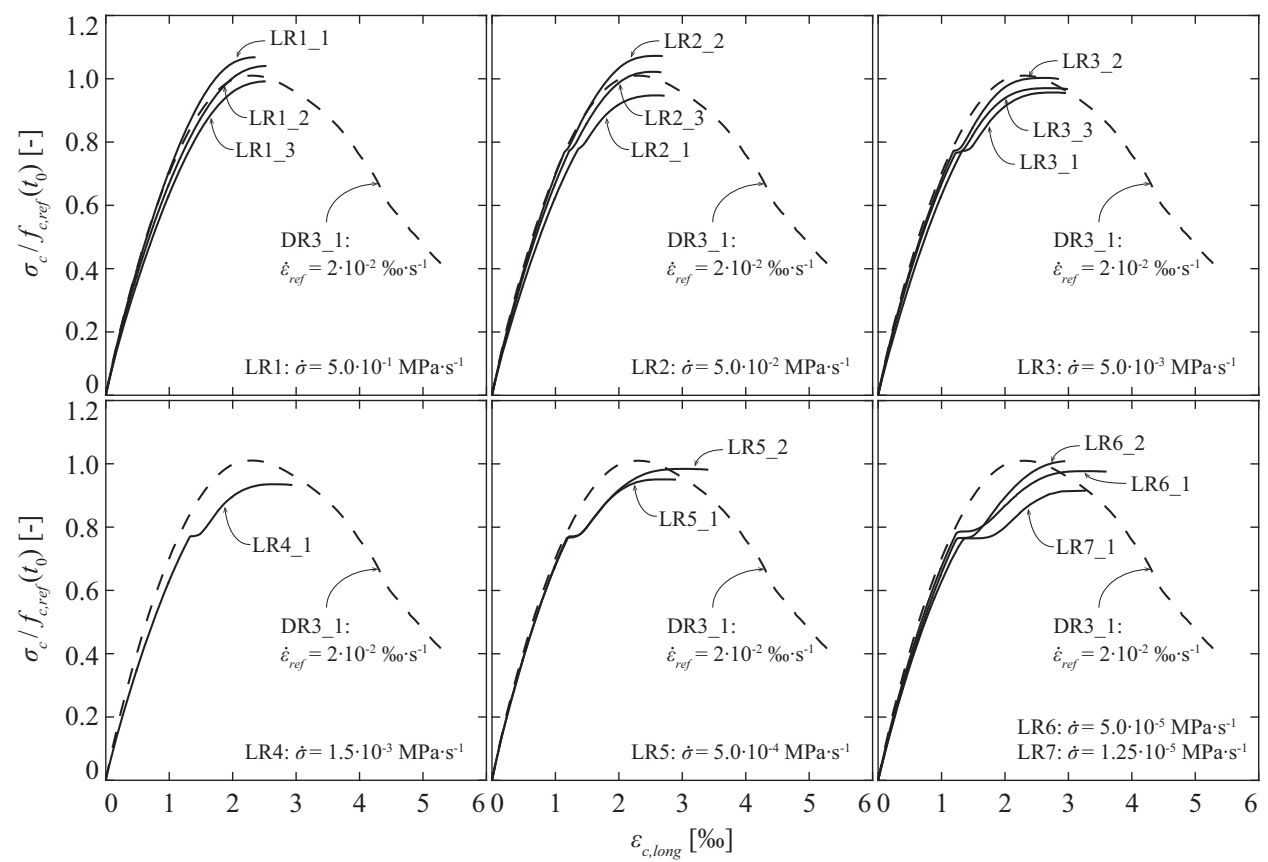

Fig. 10 Stress-strain diagrams of the $2^{\text {nd }}$ test series (tests with varying stress rate, refer to Table 3 ). 
of the instantaneous pre-peak strain $\left(\varepsilon_{c 0}\right)$, the linear creep strain $\left(\varepsilon_{c c, 1}\right)$ and the shrinkage strain $\left(\varepsilon_{c s}\right)$ have been calculated and removed from the total strain:

$$
\varepsilon_{c c, i n}=\varepsilon_{t o t}-\varepsilon_{c 0}-\varepsilon_{c c, 1}-\varepsilon_{c s}
$$
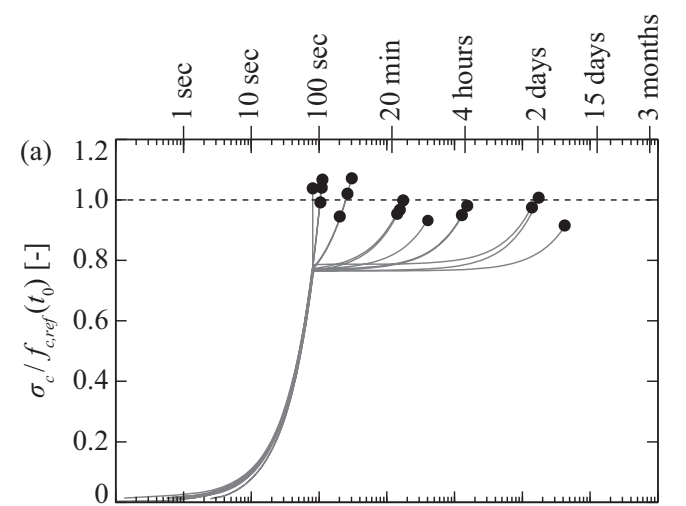

(b)

(c)

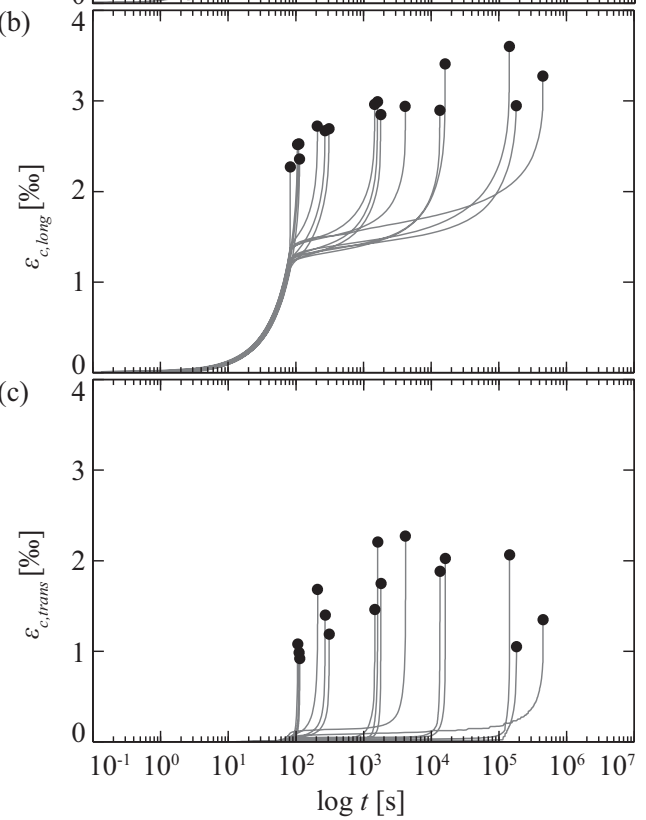

Fig. 11 Results of the $2^{\text {nd }}$ test series (tests with varying stress rate): (a) longitudinal stress; (b) longitudinal strain; and (c) transverse strain versus time.
To estimate the instantaneous pre-peak strains $\left(\varepsilon_{c 0}\right)$, the concrete model of (Fernández Ruiz et al. 2007) was used as a suitable stress-strain relationship reproducing the response of the reference tests (refer to Appendix 1). As for the linear creep and shrinkage strains, the adapted laws from Model Code 2010 as defined in Section 3.1 were used. The calculation of the creep strains due to variable stresses has been performed using the superposition principle described later in Section 4. Finally, the estimated nonlinear (inelastic) creep strains were compared to the inelastic strain capacity, as presented in Fig. 12a. The figure shows a consistent agreement between the developed inelastic strain at failure and the inelastic strain capacity (difference between post- and pre-peak strains obtained as an average of three reference test curves with $\dot{\varepsilon}=0.02 \% \mathrm{~s}^{-1}$ or the analytical expression curve of Eq. (18)). This confirms the validity of the assumptions by (Fernández Ruiz et al. 2007) also for this loading pattern.

A similar analysis has been performed for the results of a previous test series performed by the authors (Tasevski et al. 2015; Tasevski et al. 2016) by using the same loading pattern (variable strain rate). The comparison is presented in Fig. 12c and shows also an excellent agreement.

\section{(2) Stress rate tests}

In a similar manner as for the strain rate tests, the contributions of the instantaneous pre-peak strains, linear creep strains and shrinkage strains have been estimated and removed from the total strain recorded in the $2^{\text {nd }}$ test series (refer to Eq. (9)). On that basis, the estimated nonlinear (inelastic) creep strain is compared to the inelastic strain capacity, as presented in Fig. 12b.

As for the strain rate tests, an excellent agreement is found at failure between the inelastic strain capacity predicted by the reference curve and the nonlinear creep strain developed by the specimen for the various load patterns investigated, validating again the pertinence of this assumption. (a)

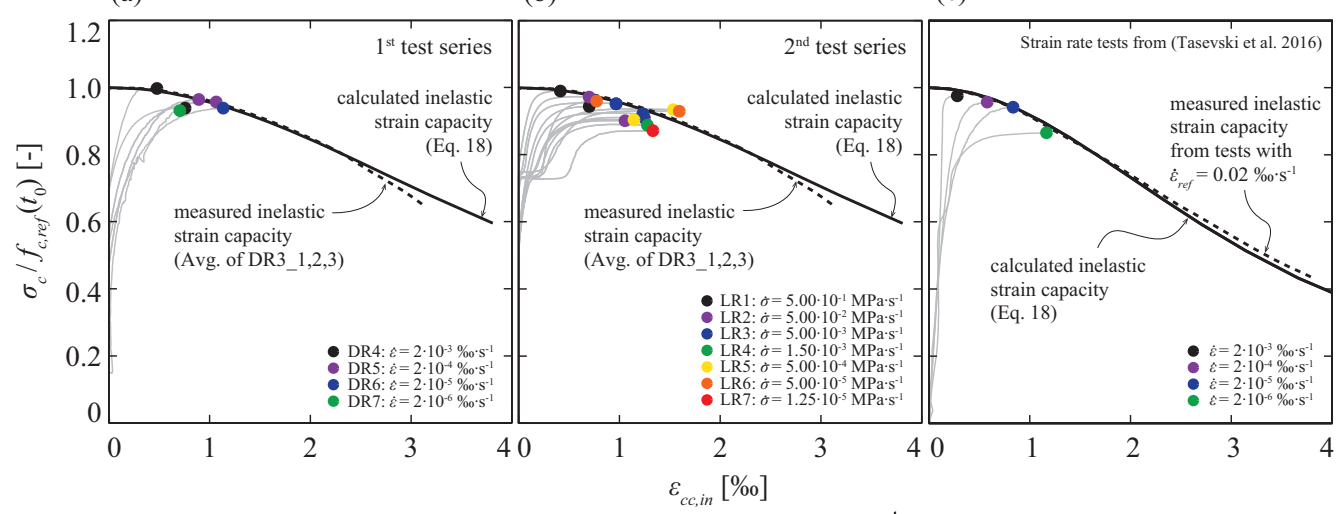

Fig. 12 Inelastic strains and corresponding inelastic strain capacity for: (a) $1^{\text {st }}$ test series with constant strain rate, (b) $2^{\text {nd }}$ test series with constant stress rate; and (c) strain rate tests from (Tasevski et al. 2016). 


\section{Analysis of linear and nonlinear creep strain development}

In this section, a simple method allowing to estimate the development of nonlinear secondary and tertiary creep strains is presented. The aim of this approach is to establish a stress-inelastic strain law based on the affinity hypothesis of creep strains (Fernández Ruiz et al. 2007) and applicable to any potential loading history. As shown in Fig. 13a, by intersecting this law with the failure criterion of inelastic strain capacity presented in Section 2.2 (and confirmed by the experimental results in Section 3.5), one can directly calculate the failure stress, the failure strain (deformation capacity) and the associated time to failure.

For extension of the framework proposed in (Fernández Ruiz et al. 2007), a distinction between primary, secondary and tertiary creep strains is performed in the following manner:

$$
\varepsilon_{c c}\left(t, t_{0}, \frac{\sigma_{c}}{f_{c}}\right)=\varepsilon_{c c, 1}\left(t, t_{0}\right)+\varepsilon_{c c, 2}\left(t, t_{0}, \frac{\sigma_{c}}{f_{c}}\right)+\varepsilon_{c c, 3}\left(t, t_{0}, \frac{\sigma_{c}}{f_{c}}, \frac{\varepsilon_{i n}}{\varepsilon_{i n, a v}}\right)
$$

where the primary creep strains are calculated by means of the linear creep coefficient:

$$
\varepsilon_{c c, 1}\left(t, t_{0}\right)=\varphi_{\text {lin }} \cdot \varepsilon_{c 0}
$$

The secondary creep strains (see Section 2.1) are evaluated as (Fernández Ruiz et al. 2007):

$$
\varepsilon_{c c, 2}\left(t, t_{0}, \frac{\sigma_{c}}{f_{c}}\right)=(\eta-1) \cdot \varepsilon_{c c, 1}\left(t, t_{0}\right)
$$

where the coefficient $\eta$ is defined in a similar manner as Eq. (4), but the expression is generalized as follows:

$$
\eta\left(\frac{\sigma_{c}}{f_{c}}, t, t_{0}\right)=\left(1+2 \cdot \eta_{\tau}\left(t, t_{0}\right)\left(\frac{\sigma_{c}}{f_{c}(t)}\right)^{4}\right)
$$

(a)

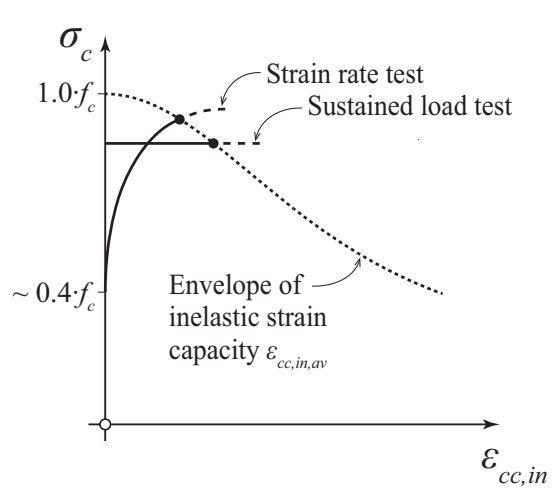

In this expression, the coefficient $\eta_{\tau}$ accounts for the development of the nonlinear creep strains with time and can be calculated as:

$$
\eta_{\tau}\left(t, t_{0}\right)=\left(1-\log \left(\frac{t-t_{0}}{t_{m}+t-t_{0}}\right)\right)^{n}
$$

The parameters $t_{m}$ and $n$ of this expression have been calibrated with the test results from the current study as well as from other literature (as later explained in Section 5.2) and can be assumed as the following constant values: $t_{m}=100$ days and $n=0.75$. It can be seen by comparing Eqs. (4) and (13) that when $t \rightarrow \infty$, both equations yield the same result and thus the coefficient $\eta_{\tau}$ is mostly influencing at early ages. The pertinence of this improvement will be justified in Section 5 by comparison to available test results (details on this phenomenon can be consulted elsewhere (Anders 2012)).

With respect to the development of tertiary creep strains, it can be assumed in agreement to (Fernández Ruiz et al. 2007) that, at the moment of failure due to tertiary creep, approximately $2 / 3$ of the total inelastic strains can be attributed to the secondary creep strains and $1 / 3$ to the tertiary creep strains, see Fig. 13b. This is a hypothesis proposed by (Fernández Ruiz et al. 2007) based on their own experimental evidence as well as experimental evidence of (Maekawa and El-Kashif 2004). The applicability of this hypothesis is confirmed in Section 5 of this paper. To evaluate the development of these tertiary creep strains, the following expression is proposed accounting for the ratio of the developed-toavailable inelastic strains $\left(\varepsilon_{c c, i n} / \varepsilon_{c c, i n, a v}\right)$ and the level of stress:

$$
\varepsilon_{c c, 3}\left(t, t_{0}, \frac{\sigma_{c}}{f_{c}}, \frac{\varepsilon_{c c, i n}}{\varepsilon_{c c, i n, a v}}\right)=\gamma\left(\frac{\sigma_{c}}{f_{c}}, \frac{\varepsilon_{c c, i n}}{\varepsilon_{c c, i n, a v}}\right) \cdot \varepsilon_{c c, 2}\left(t, t_{0}, \frac{\sigma_{c}}{f_{c}}\right)
$$

For low values of $\varepsilon_{c c, i n} / \varepsilon_{c c, i n, a v}$, the contribution of tertiary creep strains is negligible (almost no crack coalescence), whereas it increases at a growing rate (unstable crack coalescence) close to failure. On the basis of the

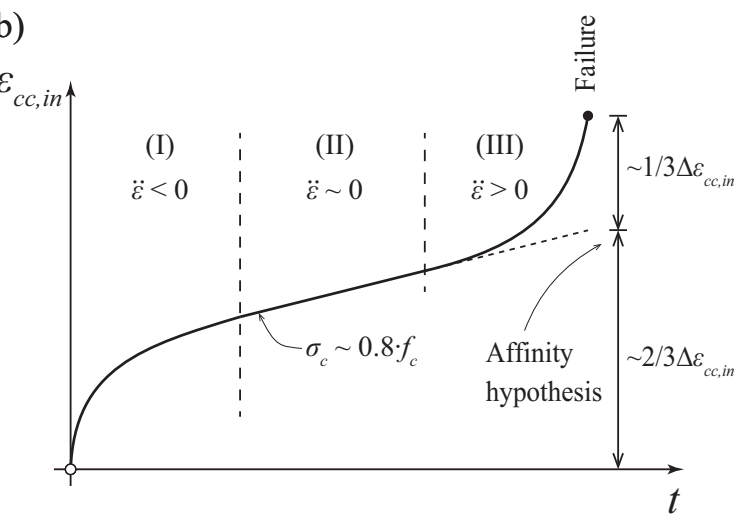

Fig. 13 Development of inelastic strains with time: (a) failure calculated by intersection of the stress-inelastic strain curve and the failure criterion of the inelastic strain capacity; and (b) inelastic creep strain development with time based on the affinity hypothesis for a sustained load test, adapted from (Fernández Ruiz et al. 2007). 
Table 4 Comparison of calculated failure stress and strain and test results.

\begin{tabular}{|c|c|c|c|c|c|c|}
\hline \multirow{2}{*}{ Test Name } & \multicolumn{3}{|c|}{$f_{c, \Delta t} / f_{c, r e f}\left(t_{0}\right)$} & \multicolumn{3}{|c|}{$\varepsilon_{c_{2} \text { long }}$} \\
\hline & $\begin{array}{c}\text { calc. } \\
{[-]}\end{array}$ & $\begin{array}{c}\text { tested } \\
{[-]}\end{array}$ & $\begin{array}{c}\text { tested / calc. } \\
{[-]}\end{array}$ & $\begin{array}{l}\text { calc. } \\
{[\% 0]}\end{array}$ & $\begin{array}{c}\text { tested } \\
{[\% 0]}\end{array}$ & $\begin{array}{c}\text { tested / calc. } \\
{[-]}\end{array}$ \\
\hline DR4_2 & 0.974 & 0.999 & 1.026 & 2.05 & 2.62 & 1.28 \\
\hline DR5_1 & 0.953 & 0.966 & 1.014 & 2.41 & 2.81 & 1.17 \\
\hline DR5_2 & 0.953 & 0.959 & 1.006 & 2.41 & 2.95 & 1.22 \\
\hline DR6_1 & 0.935 & 0.939 & 1.004 & 2.78 & 3.09 & 1.11 \\
\hline \multirow[t]{4}{*}{ DR7_1 } & \multirow[t]{4}{*}{0.906} & 0.932 & 1.029 & \multirow[t]{4}{*}{3.18} & 2.94 & 0.925 \\
\hline & & Avg & 1.016 & & Avg & 1.14 \\
\hline & & StDev & 0.011 & & StDev & 0.136 \\
\hline & & $\mathrm{CoV}$ & 0.011 & & $\mathrm{CoV}$ & 0.119 \\
\hline LR3_1 & 0.985 & 0.954 & 0.969 & 2.29 & 2.96 & 1.29 \\
\hline LR3 2 & 0.982 & 1.00 & 1.02 & 2.31 & 2.85 & 1.23 \\
\hline LR3 3 & 0.983 & 0.968 & 0.985 & 2.30 & 2.99 & 1.30 \\
\hline LR4_1 & 0.973 & 0.933 & 0.959 & 2.40 & 2.94 & 1.23 \\
\hline LR5_1 & 0.955 & 0.949 & 0.994 & 2.56 & 2.90 & 1.13 \\
\hline LR5_2 & 0.952 & 0.981 & 1.03 & 2.58 & 3.41 & 1.32 \\
\hline LR6_1 & 0.903 & 0.977 & 1.08 & 2.96 & 3.60 & 1.22 \\
\hline LR6_2 & 0.897 & 1.01 & 1.13 & 3.02 & 2.95 & 0.977 \\
\hline \multirow[t]{4}{*}{ LR7_1 } & \multirow[t]{4}{*}{0.874} & 0.914 & 1.05 & \multirow[t]{4}{*}{3.21} & 3.28 & 1.022 \\
\hline & & Avg & 1.023 & & Avg & 1.191 \\
\hline & & StDev & 0.055 & & StDev & 0.123 \\
\hline & & $\mathrm{CoV}$ & 0.054 & & $\mathrm{CoV}$ & 0.103 \\
\hline
\end{tabular}

experimental results of this paper (a comparison is presented in Section 5.1), it is proposed to evaluate the value of the parameter $\gamma$ according to:

$$
\begin{array}{ll}
\gamma=0 & \text { for } \sigma_{c} / f_{c}(t)<0.75 \\
\gamma=\frac{1}{2} \cdot\left(\frac{\varepsilon_{c c, i n}}{\varepsilon_{c c, i n, a v}(t)}\right)^{\alpha} & \text { for } \sigma_{c} / f_{c}(t) \geq 0.75
\end{array}
$$

where $\gamma$ is only non-zero for stress levels above the assumed tertiary creep threshold of $\sigma_{c} / f_{c}=0.75$, according to (Rüsch 1960). The parameter $\alpha$ governs the shape of the tertiary creep strain development and can reasonably be set equal to $\alpha=4$. It can be noted that when $\varepsilon_{c c, i n}=\varepsilon_{c c, i n, a v}$ (failure), it results $\varepsilon_{c c, 3}=1 / 2 \varepsilon_{c c, 2}$, which is consistent with the assumption that $\varepsilon_{c c, 2}=2 / 3 \varepsilon_{c c, i n, a v}$ and $\varepsilon_{c c, 3}=1 / 3 \varepsilon_{c c, i n, a v}$ (refer to Fig. 13b).

With respect to a variable loading history, the strain development can finally be calculated using the superposition principle as:

$$
\begin{aligned}
\varepsilon_{c}(t) & =\sum_{i=1}^{n}\left[\varepsilon _ { c 0 } ( \sigma _ { c , i } ) \left(1+\left[\eta\left(\frac{\sigma_{c, i}}{f_{c, i}}\right)+\gamma\left(\frac{\sigma_{c, i}}{f_{c, i}}, \frac{\varepsilon_{c c, i n, i}}{\varepsilon_{c c, i n, a v}}\right)\right.\right.\right. \\
& \left.\left.\cdot\left(\eta\left(\frac{\sigma_{c, i}}{f_{c, i}}\right)-1\right)\right] \cdot \varphi\left(t, t_{i}\right)\right)-\varepsilon_{c 0}\left(\sigma_{c, i-1}\right)\left(1+\left[\eta\left(\frac{\sigma_{c, i-1}}{f_{c, i-1}}\right)\right.\right. \\
& \left.\left.\left.+\gamma\left(\frac{\sigma_{c, i-1}}{f_{c, i-1}}, \frac{\varepsilon_{c c, i n, i-1}}{\varepsilon_{c c, i n, a v}}\right) \cdot\left(\eta\left(\frac{\sigma_{c, i-1}}{f_{c, i-1}}\right)-1\right)\right] \cdot \varphi\left(t, t_{i}\right)\right)\right] \\
& +\left(\varepsilon_{c s}\left(t, t_{s}\right)-\varepsilon_{c s}\left(t_{1}, t_{s}\right)\right)
\end{aligned}
$$

This approach has been shown to be licit in combination with the affinity hypothesis of linear and nonlinear creep strains (Fernández Ruiz 2003) and considers the actual (nonlinear) instantaneous pre-peak strain for the applied level of stress (calculation of $\varepsilon_{c 0}\left(\sigma_{c}\right)$ according to
Appendix 1). It can also be noted that this formula accounts for the concrete strength at the time of evaluation, and thus allows automatically to consider the increase of the concrete strength with time.

A comparison of this approach to the test results presented in this paper is discussed in the next section. It can be noted that this comparison is performed for standard cylinder dimensions (those described in Section 3) typically used to characterize the compressive strength of concrete (a generalization to other potential geometries or sizes remains outside the scope of this work).

\section{Comparison to test results}

\subsection{Own experimental programme}

Eq. (17) was applied to predict the strain development of the experimental programme presented in Section 3. On that basis, and by intersecting it with the failure criterion defined by the inelastic strain capacity of Eq. (18), the failure load can be calculated. The results are compared in Fig. 14 for the $1^{\text {st }}$ and $2^{\text {nd }}$ test series (variable strain rate and stress rate respectively) as well as for the test series of Tasevski et al. (Tasevski et al. 2015; Tasevski et al. 2016).

The comparison shows a sound and consistent agreement for the various series both in terms of the strength and deformation capacity (detailed values presented in Table 4). In addition, the presented model suitably captures the observed experimental trends of decreasing strength and increasing deformation at failure for increasing time of application of the stress (Fig. 14). The results are also observed to be consistently reproduced for the two types of loading pattern investigated. 


\subsection{Tests with constant sustained stress}

An additional validation of the proposed approach is performed by investigating tests from the research group of Rüsch (Rüsch 1960; Rüsch et al. 1968) and later re-evaluated by Grasser and Kraemer (Grasser and Kraemer 1985) on concrete specimens failing in compression under constant sustained stress. Also the experimental programmes by (Shank 1949; Awad and Hilsdorf 1971; Smadi et al. 1985; Iravani and MacGregor 1998) are included in the comparison. To estimate the shrinkage strains, a similar strategy has been applied as in Section 3.1 (the Model Code 2010 formula has been adapted to best fit the shrinkage data provided in (Rüsch et al. 1968)). The effect of aging has been considered by using Eq.(6), where the coefficient $s$ has been set equal to 0.25 . Furthermore, to distinguish between linear and nonlinear creep strains, the primary creep development has been estimated from the curve at sustained stress level of $\sigma_{c} / f_{c}=0.4$.

The results are plotted in Fig. 15 (Figures a-c com- (a)

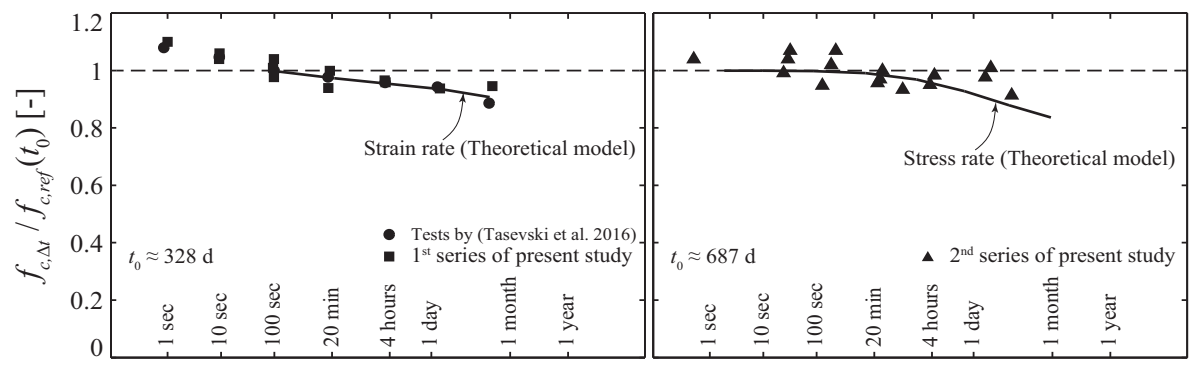

(c)

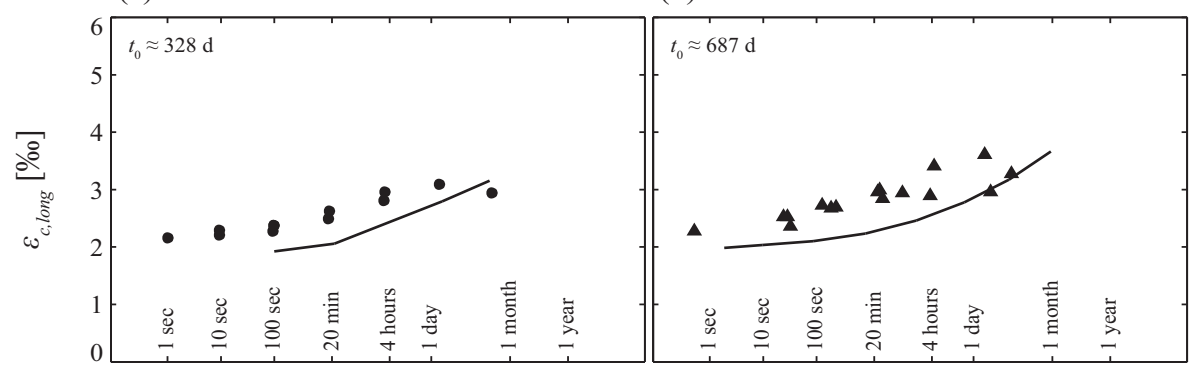

$\log \Delta t$

(b)

(d)

Fig. 14 Comparison of theoretical model and test results: (a) strength for strain rate tests; (b) strength for stress rate tests; (c) deformation at failure for strain rate tests; and (d) deformation at failure for stress rate tests.

(a)

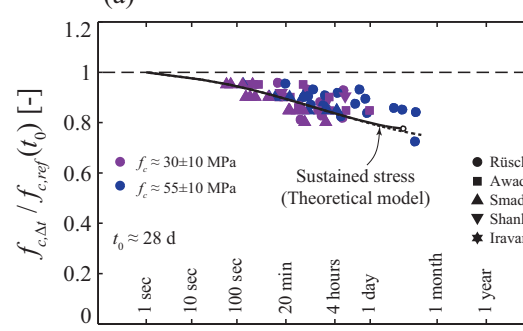

(d)

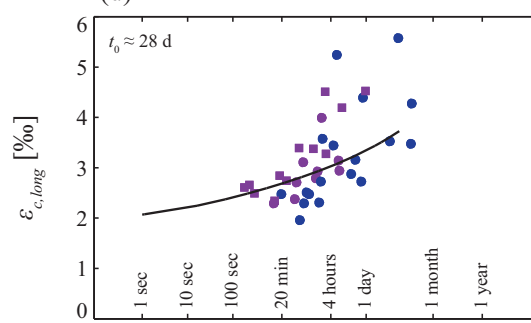

(b)

(c)

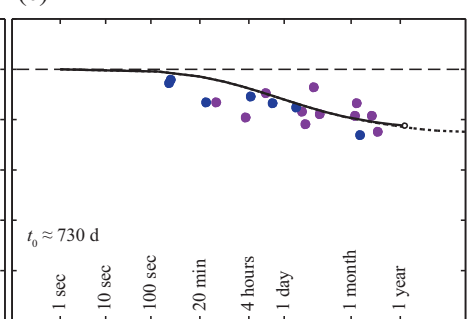

(e)

(f)

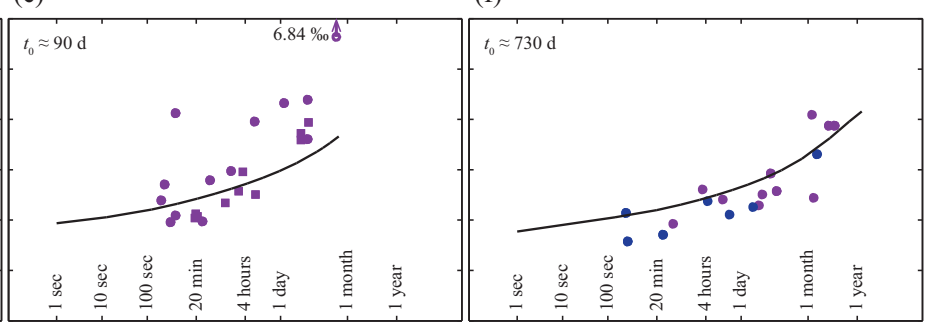

$\log \Delta t$

Fig. 15 Comparison of the proposed model to test results: (a-c) influence of sustained loading duration $\Delta t$ on strength for different loading ages (28, 90 and 730 days respectively); and (d-f) influence on strain capacity. Solid line representing the analysis with increase of strength of concrete with time; dashed line representing the analysis without considering this effect. The model curves have been calculated for an average value $f_{c, 28}=40 \mathrm{MPa}$. 
paring the strength and Figures d-f comparing the strain at failure). Figure 15 shows that a very good and consistent estimate is again obtained both in terms of strength and strain prediction. The model is able to capture the effect of long-term loading both on the decrease of strength as well as the increase of deformation capacity. This fine agreement between the tests and the prediction further confirms the applicability of the affinity hypothesis of nonlinear creep presented in Section 4 of this paper (both for experiments on sustained loads from literature and for the own experimental programme on strain and stress rate tests).

It can be noted that, in the plots of strength (Figs. 15a - 15c), two curves are provided. The dotted one corresponds to the analysis where failure is considered to occur without increase of concrete strength with time (no consideration of ageing influence), while the solid one accounts for this phenomenon. The main difference between both analyses can be seen in the fact that when the concrete ageing is considered (solid line), failures can develop only for smaller times and higher load levels than when this effect is not considered (dashed line). This can be seen in Figs. 15a - 15c by the circle indicated at the end of the solid line (considering concrete

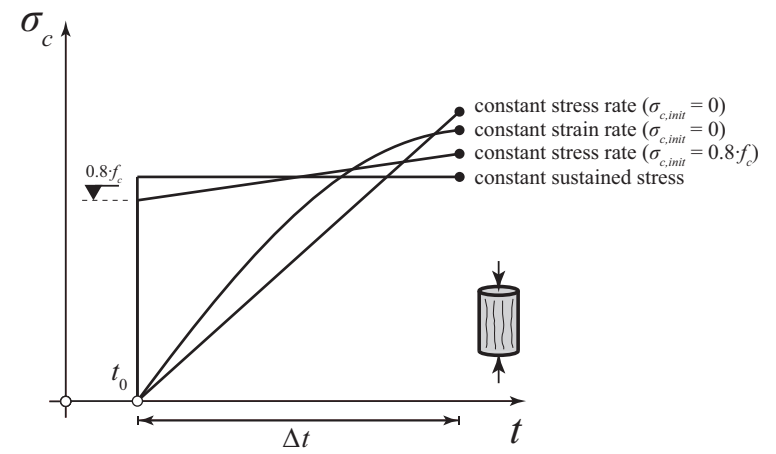

Fig. 16 Loading patterns investigated: constant sustained stress, constant strain rate, constant stress rate and constant stress rate applied after rapid loading up to $80 \%$ of material strength.

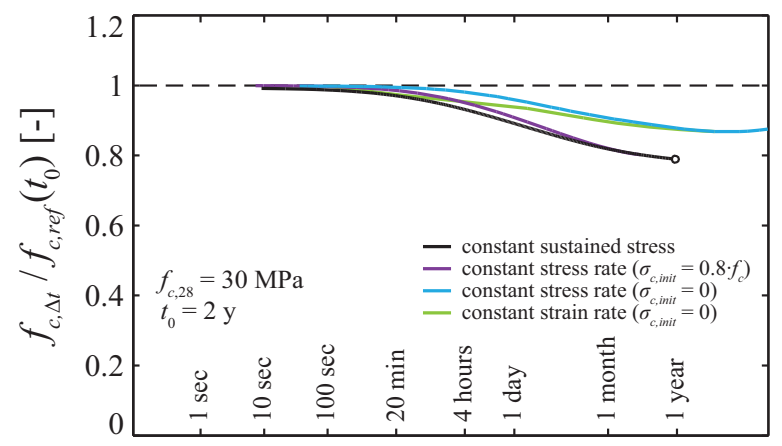

$\log \Delta t$

Fig. 17 Comparison of the calculated response for different types of loading: constant sustained stress, constant strain rate, constant stress rate and constant stress rate applied after rapid loading up to $80 \%$ of material strength. ageing), which corresponds to the last calculated point where failure under sustained loading can occur. After this point, the curve would theoretically raise (Rüsch 1960), although this part of the curve is physically not relevant with the described loading pattern. The results of the theoretical model also confirm the observations on this issue already stated by (Rüsch 1960) that failure is not prone to occur after a certain time when concrete is loaded at an early age (refer to Fig. 15a, the increase of strength with time is more significant than the progress of damage in the member). When the concrete is loaded at older ages, however, failures can occur after significant periods of time (refer to Fig. 15c).

The fact that the model is strain-based (and can thus predict the deformation capacity at failure) can additionally be considered as a significant quality. This allows understanding that, other than a detrimental effect on the strength of concrete, long-term actions also have a potential positive effect in redundant systems as the increased strains (more than proportionally) allow load to be redistributed from more stressed regions to less stressed regions of the structure (and for instance activate compression reinforcement).

\section{Parametric analyses}

Taking advantage of the model presented in Section 4, some issues will be parametrically investigated in this section, namely the influence on the long-term response of concrete of the loading pattern, the ageing of concrete (increase of strength with time), the time at loading and the concrete strength.

\subsection{Influence of loading pattern}

The influence of the loading pattern on the concrete strength has been a matter of discussion since long. Rüsch (Rüsch 1960) already presented some considerations on the difference between the compressive strength of tests performed at constant strain rates and tests performed at sustained stress levels. His main conclusion was that "constant loads lead to somewhat lower failure loads than loading at constant strain rates". Based on the main assumptions made in Section 4 of this paper, this (purely observational) conclusion of Rüsch can be confirmed from a theoretical point of view. To that aim, four loading patterns will be investigated: a constant sustained stress, a constant strain rate, a constant stress rate and a constant stress rate following a rapid loading ramp up to $80 \%$ of the material short-term strength (see Fig. 16).

The comparison of the response of concrete is presented in Fig. 17 for a standard case $\left(f_{c, 28}=30 \mathrm{MPa}\right.$, load applied two years after casting). The results show that failures under constant sustained stress occur earlier and for lower load levels than for the other loading patterns. This is in agreement with Rüsch's observations and is logical as concrete is subjected to higher stress levels since the beginning of the loading process (allow- 
ing for the propagation and coalescence of microcracks). For the same reason, from the three other cases, the constant stress rate starting at $80 \%$ of the material strength yields also to larger strength reductions than the constant strain and stress rates. Comparing the strain and stress rates, the strain rate, where the stress level remains fairly constant near failure, leads also (consistently to the other results) to larger strength reductions than the constant stress rate.

\subsection{Influence of concrete ageing}

Another important phenomenon that was already discussed in Section 5.2 is the influence of concrete ageing on the long-term response of the material (increase of concrete strength with age, potentially compensating for the detrimental effect of the sustained loading). Fig. 18 presents with this respect three plots prepared for identical concrete specimens but with different loading times and values of the parameter $s$ (different strength classes of cement affecting the concrete ageing, refer to Eq. (6)). In the abscissa, the long-term strength is normalized with respect to the reference strength at 28 days in order to compare the absolute variations of strength.

As it can be seen in Fig. 18, when concrete is loaded

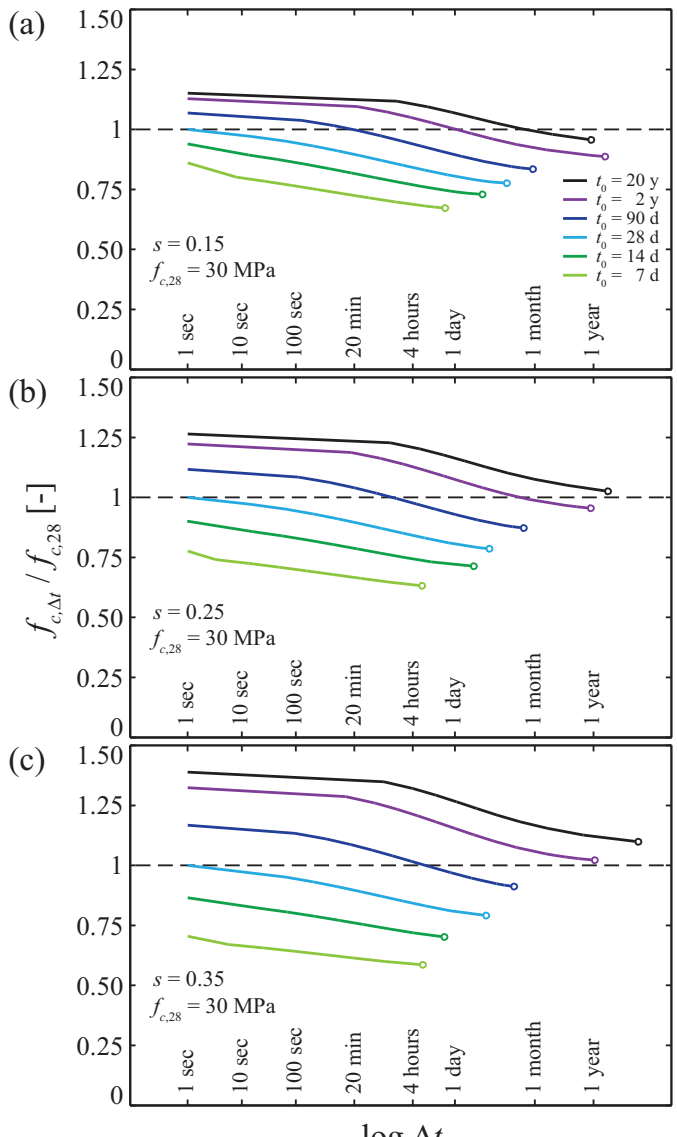

Fig. 18 Parametric analysis of the effect of the duration of sustained loading $\Delta t$ for different ages at initial loading ages $t_{0}$ (strength increase with concrete age considered normalized with the reference strength at 28 days):

(a) $s=0.15$; (b) $s=0.25$ and (c) $s=0.35$. at an early age, failure under sustained stress, if happens, occurs in a very limited period of time (1 day to 1 week) Thereafter, the increase of strength with time compensates for the material damage. For concrete loaded at older ages, however, failures can occur during longer periods of sustained stress (even more than one year) as little gain of the strength occurs. This result is consistent with Rüsch's conclusions (Rüsch 1960).

Additionally, it can be observed that when the concrete is loaded at old ages (black curves in Fig. 18), there is a large decrease of the strength under sustained loading. Yet, the long-term strength is normally similar or even higher to the one expected at 28 days (indicated by the value 1.0) as the concrete increased its strength prior to the loading process.

\subsection{Influence of concrete strength and time at loading}

Finally, some additional results are presented in Fig. 19 with reference to the influence of concrete strength and time at loading. The influence of the concrete strength on the long-term loading (Fig. 19c) is not very sensitive. However, this parameter shows a very significant influence on the deformation capacity at failure (Fig. 19d). This is mostly justified by the fact that the maximum strength of higher concrete grades is developed for larger strain values.

With respect to the strength decrease depending on the age at loading (Fig. 19a), this parameter was already investigated and discussed in Section 6.2. Regarding the deformation capacity at failure (Fig. 19b), it can be seen that this parameter has a significant influence, with development of larger values of the deformations at failure for concrete members loaded at earlier ages. This result is justified by the fact that older concretes develop lower creep strains (linear and nonlinear) for the same duration of the load and are thus associated to lower deformation levels at failure.

\section{Conclusions}

This paper investigates on the development of linear and nonlinear creep strains potentially leading to failure under high levels of load. New experimental data is presented on loading patterns with variable strain and stress rates as well as an analytical approach allowing to consistently investigate these cases. The main conclusions of this paper are:

1) On the basis of the experimental results presented in this paper, failure under long-term load is shown to be governed by the inelastic strain capacity of concrete. When the developed inelastic strain of concrete equals the inelastic strain capacity, failure occurs by progressive coalescence of cracks. This result is confirmed for all the investigated loading patterns (constant sustained load, strain rate and stress rate).

2) The inelastic strain capacity can be estimated as the 
(a)

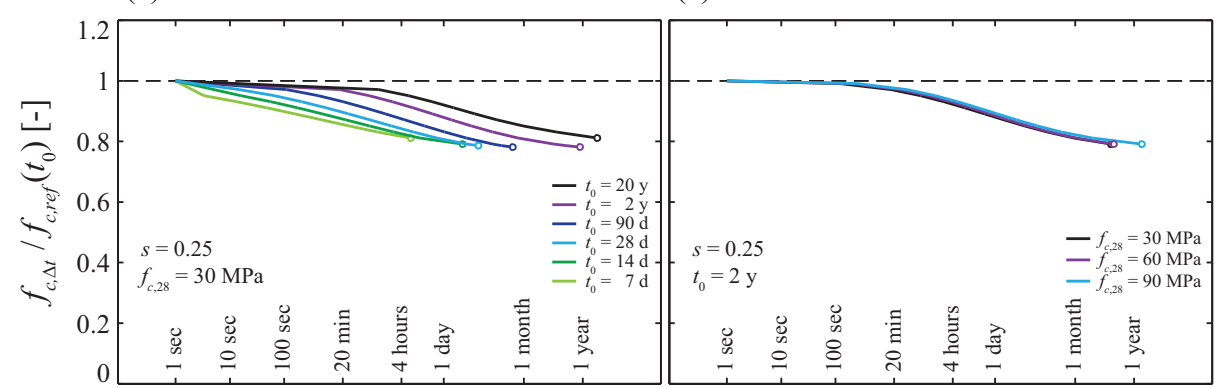

(b)

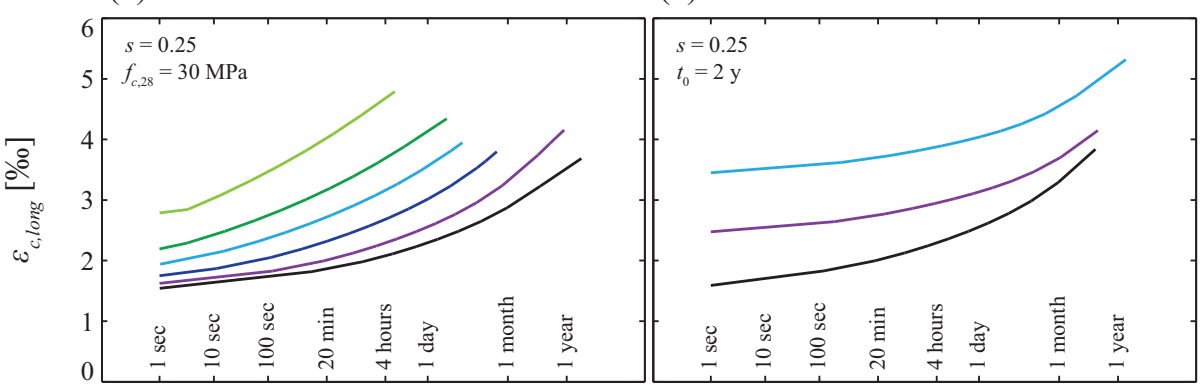

$\log \Delta t$

Fig. 19 Parametric analysis (strength increase with concrete age considered, strength normalized to the reference strength at the time of loading) of the effect of sustained loading $\Delta t$ for different loading ages on: (a) strength; (b) strain at failure; and effect of concrete strength on: (c) strength; and (d) strain at failure.

difference between the instantaneous post- and prepeak strains for a given stress level. This allows defining a failure criterion for the available inelastic strain capacity.

3) The affinity assumption between linear and nonlinear creep strains (Fernández Ruiz et al. 2007) can be used as a simple and efficient tool to estimate the development of inelastic strains in concrete for a given loading history. The formulation of this approach has been extended in this paper:

a. To be applicable to any potential loading pattern.

b. To be applicable to failures at early age.

c. To account in an explicit manner for the development of tertiary creep strains.

The pertinence of this approach and new formulations has been validated with the experimental results presented in this manuscript.

4) Analytical calculation of failures under long-term loading patterns can be performed as the intersection between the relationship defining the development of inelastic strains for a given loading pattern (based on the affinity assumption) and the failure criterion defined by the inelastic strain capacity of concrete. This approach, confirmed by the experimental results presented in this paper as well as others from the scientific literature, allows to consistently estimate:

a. The reduction of the strength due to sustained loading or low strain or stress rates. This is a detrimental effect in members subjected to high stresses.

b. The increase of strains at failure. The evaluation of this effect, many times not explicitly acknowledged in design formulations, might nevertheless be an instrumental positive effect for statically redundant systems, where redistributions of stresses are possible from more stressed regions to less stressed regions and increasingly activate compression reinforcement.

5) On the basis of the theoretical model, some effects can be clearly reproduced and investigated, for instance:

a. Constant sustained stress patterns lead to failures at lower stress levels and more rapidly than for stress or strain rates (concrete is subjected to higher stress levels since the beginning of the loading process).

b. Ageing of the concrete (increase of concrete strength with time) is observed to be an instrumental phenomenon as it compensates for the material damage. For concretes loaded at early ages, failure can only occur after some hours or days, while for concretes loaded at older ages, failures under long-term load can occur several years after (as there is almost no increase of strength due to ageing).

\section{Acknowledgements}

The authors acknowledge the financial support from the Swiss Federal Roads Office (FEDRO), project No. AGB-2013-001.

\section{References}

Aili, A., Vandamme, M., Torrenti, J.-M. and Masson, B., 
(2015). “Theoretical and practical differences between creep and relaxation Poisson's ratios in linear viscoelasticity." Mechanics of Time-Dependent Materials, 19(4), 537-555.

Anders, I., (2012). "Material law for description of creep and relaxation behavior of young normalstrength and high-strength concretes." (in German: "Stoffgesetz zur Beschreibung des Kriech- und Relaxationsverhaltens junger normal- und hochfester Betone."). Thesis (PhD). Karlsruhe Institute of Technology. $157 \mathrm{p}$.

Awad, M. E. and Hilsdorf, H. K., (1971). "Strength and deformation characteristics of plain concrete subjected to high repeated and sustained loads." Report. Structural Research Series, No. 372, University of Illinois, $266 \mathrm{p}$.

Barpi, F. and Valente, S., (2005). "Lifetime evaluation of concrete structures under sustained post-peak loading." Engineering Fracture Mechanics, 72(16), 2427-2443.

Bažant, Z. P., (1970). "Constitutive equation for concrete creep and shrinkage based on thermodynamics of multiphase systems." Materials and Structures, 3(13), 3-36.

Bažant, Z. P. and Xiang, Y., (1997). "Crack growth and lifetime of concrete under long time loading." $A S C E$ Journal of Engineering Mechanics, 123(4), 350-358.

Benboudjema, F., Meftah, F., Sellier, A., Heinfling, G. and Torrenti, J.-M., (2001). "A Basic creep model for concrete subjected to multiaxial loads." In: Proceedings of the $4^{\text {th }}$ International Conference on Fracture Mechanics of Concrete and Concrete Structures, Cachan 28-31 May 2001, 161-168.

Berthollet, A., Georgin, J.-F. and Reynouard, J.-M., (2004). "Tertiary creep of concrete in tension." (in French: "Fluage tertiaire du béton en traction."). Revue Française de Génie Civil, 8(2-3), 235-260.

Bockhold, J. and Stangenberg, F., (2004). "Modelling of nonlinear creep of concrete." (in German: "Modellierung des nichtlinearen Kriechens von Beton.") Beton- und Stahlbetonbau, 99(3), 209-216.

Carpinteri, A., Valente, S., Zhou, F. P., Ferrara, G. and Melchiorri, G., (1997). "Tensile and flexural creep rupture tests on partially-damaged concrete specimens." Materials and Structures, 30(5), 269-276.

CEN European Committee for Standardization, (2004). "Eurocode 2. Design of concrete structures - General rules and rules for buildings, EN 1992-1-1." Brussels, Belgium. 225 p.

Coutinho, S. A., (1977). "A contribution to the mechanism of concrete creep." Materials and Structures, 10(55), 3-16.

Davis, R. E., (1928). "Flow of concrete under sustained compressive stress." ACI Journal, 24(2), 303-326.

Denarié, E., Cécot, C. and Huet, C., (2006). "Characterization of creep and crack growth interactions in the fracture behavior of concrete." Cement and Concrete Research, 36(3), 571-575.
Diaz, S. I. and Hilsdorf, H. K., (1971). "Fracture mechanics of concrete under static, sustained and repeated compressive loads." Report. Structural Research Series, No. 382, University of Illinois, 198 p.

Domone, P. L., (1974). "Uniaxial tensile creep and failure of concrete." Magazine of Concrete Research, 26(88), 144-152.

El-Kashif, K. F. and Maekawa, K., (2004). "Timedependent nonlinearity of compression softening in concrete." Journal of Advanced Concrete Technology, 2(2), 233-247.

Fernández Ruiz, M., (2003). "Nonlinear analysis of the structural effects of the delayed strains of steel and concrete." (in Spanish: "Evaluación no lineal de los efectos estructurales producidos por las deformaciones diferidas del hormigón y el acero."). Thesis (PhD). Polytechnic University of Madrid. Ed. ACHE, $175 \mathrm{p}$.

Fernández Ruiz, M., Muttoni, A. and Gambarova, P. G., (2007). "Relationship between nonlinear creep and cracking of concrete under uniaxial compression." Journal of Advanced Concrete Technology, 5(3), 383393.

fib Fédération internationale du béton, (2013). " $\mathrm{fib}$ Model Code for concrete structures 2010." Germany, Ernst and Sonh, $434 \mathrm{p}$.

Fischer, I., Pichler, B., Lach, E., Terner, Ch., Barraud, E. and Britz, F., (2014). "Compressive strength of cement paste as a function of loading rate: Experiments and engineering mechanics analysis." Cement and Concrete Research, 58, 186-200.

Fouré, B., (1985). "Long-term strength of concrete under sustained loading." (in French: "Résistance potentielle à long terme $d u$ béton soumis à une contrainte soutenue."). Report. Annales de l'Institut Technique du Bâtiment et des Travaux Publics, No. 431, Paris, France, 45-64.

Freudenthal, A. M. and Roll, F., (1958). "Creep and creep recovery of concrete under high compressive stress." ACI Journal, 54(6), 1111-1142.

Goodman, R. E., (1989). "Introduction to rock mechanics." 2nd ed. New York: John Wiley \& Sons, $576 \mathrm{p}$.

Grasser, E. and Kraemer, U., (1985). "Creep of concrete under high centric and eccentric compressive load." (in German: "Kriechen von Beton unter hoher zentrischer und exzentrischer Druckbeanspruchung."). Report. Deutscher Ausschuss für Stahlbeton, Vol. 358, Ed. Berlin: Beuth, 84 p.

Han, N. and Walraven, J. C., (1994). "Properties of high-strength concrete subjected to uniaxial loading." ACI Special Publication, 149, 269-288.

Iravani, S. and MacGregor, J. G., (1998). "Sustained load strength and short-term strain behavior of highstrength concrete." ACI Materials Journal, 95(5), 636-647.

Karsan, A.I. and Jirsa, J. O., (1969). "Behavior of 
concrete under compressive loadings." ASCE Journal of the Structural Division, 95, 2535-2563.

Maekawa, K. and El-Kashif, K. F., (2004). "Cyclic cumulative damaging of reinforced concrete in postpeak regions." Journal of Advanced Concrete Technology, 2(2), 257-271.

Mazzotti, C. and Savoia, M., (2002). "Nonlinear creep, Poisson's ratio, and creep-damage interaction of concrete in compression." ACI Materials Journal, 99(5), 450-457.

Müller, H. S., Burkart, I., Budelmann, H, Ewert, J., Mechtcherine, V., Dudziak, L., Müller, Ch. and Eppers, S., (2010). "Time-dependent behaviour of ultra high performance concrete (UHPC)." In: Proceedings of the $3^{\text {rd }}$ International fib Congress, Washington D.C. 29 May - 2 June 2010, 15 p.

Nechvatal, D., Stöckl, S. and Kupfer, H., (1994). “Creep, creep recovery and sustained load strength of concrete at different moisture content and use of Portland cement and Portland-Limestone cement." (in German: "Kriechen, Rückkriechen und Dauerstandfestigkeit von Beton bei unterschiedlichem Feuchtegehalt und Verwendung von Portlandzement und Portlandkalksteinzement."). Report. Deutscher Ausschuss für Stahlbeton, Vol. 442, Ed. Berlin: Beuth, 55-99.

Ngab, A. S., Nilson, A. H. and Slate, F. O., (1981). "Shrinkage and creep of high strength concrete." $A C I$ Journal, 78(4), 255-261.

Omar, M., Loukili, A., Pijaudier-Cabot, G. and Le Pape, Y., (2009). "Creep-damage coupled effects: experimental investigation on bending beams with various sizes." Journal of Materials in Civil Engineering, 21(2), 65-72.

Reinhardt, H.-W. and Cornelissen, H. A. W., (1985). "Sustained tensile tests of concrete." (in German: "Zeitstandzugversuche an Beton."). Report. Baustoffe '85, Karlhans Wesche gewidmet, Ed. Bauverlag Wiesbaden, 162-167.

Reinhardt, H.-W. and Rinder, T., (2006). "Tensile creep of high-strength concrete." Journal of Advanced Concrete Technology, 4(2), 277-283.

Rinder, T., (2003). "High strength concrete under sustained tensile load." (in German: "Hochfester Beton unter Dauerzuglast.") Report. Deutscher Ausschuss für Stahlbeton, Vol. 544, Ed. Berlin: Beuth, $134 \mathrm{p}$.

Roll, F., (1964). "Long-time creep-recovery of highly stressed concrete cylinders." ACI Special Publication, 9, 95-114.

Rossi, P., Godart, N., Robert, J. L., Gervais, J. P. and Bruhat, D., (1994). "Investigation of the basic creep of concrete by acoustic emission." Materials and Structures, 27(9), 510-514.

Rossi, P., Tailhan, J.-L., Le Maou, F., Gaillet, L. and Martin, E., (2012). "Basic creep behavior of concretes investigation of the physical mechanisms by using acoustic emission." Cement and Concrete
Research, 42(1), 61-73.

Rossi, P., Tailhan, J.-L. and Le Maou, F., (2013). "Creep strain versus residual strain of a concrete loaded under various levels of compressive stress." Cement and Concrete Research, 51, 32-37.

Rüsch, H., (1956). "Experimental determination of the effect of the duration of loading on the resistance and deflection." (in German: "Versuche zur Bestimmung des Einflusses der Zeit auf Festigkeit und Verformung."). Report. IABSE congress report, 5, 237-244.

Rüsch, H., (1960). "Researches toward a general flexural theory for structural concrete." ACI Journal, 57(1), 1-28.

Rüsch, H., Sell, R., Rasch, C., Grasser, E., Hummel, A., Wesche, K. and Flatten, H., (1968). "Strength and deformation of plain concrete under sustained loading." (in German: "Festigkeit und Verformung von unbewehrtem Beton unter konstanter Dauerlast."). Report. Deutscher Ausschuss für Stahlbeton, Vol. 198, Ed. Berlin: Wilhelm Ernst and Sohn, 86 p.

Schlappal, T., Schweigler, M., Gmainer, S., Peyerl, M. and Pichler, B., (2017). "Creep and cracking of concrete hinges: insight from centric and eccentric compression experiments." Materials and Structures, 50(244), 1-16.

Shah, S. P. and Chandra, S., (1970). "Fracture of concrete subjected to cyclic and sustained loading." ACI Journal Proceedings, 67(10), 816-827.

Shank, J. R., (1949). "Plastic flow of concrete at high overload." ACI Journal, 45(2), 493-498.

Smadi, M. M., (1983). "Time-dependent behavior of high-strength concrete under high sustained compressive stresses." Thesis (PhD). Cornell University. 297 p.

Smadi, M. M., Slate, F. O. and Nilson, A. H., (1985). "High-, medium-, and low-strength concretes subject to sustained overloads - Strains, strengths, and failure mechanisms." ACI Journal, 82(5), 657-664.

Stöckl, S., (1972). "Strength of concrete under uniaxial sustained loading." ACI Special Publication, 34, 313326.

Suryanto, B., Maekawa, K. and Nagai, K., (2013). "Predicting the creep strain of PVA-ECC at high stress levels based on the evolution of plasticity and damage." Journal of Advanced Concrete Technology, 11(2), 35-48.

Tasevski, D., Fernández Ruiz, M. and Muttoni, A., (2015). "Analogy between sustained loading and strain rate effects on the nonlinear creep response of concrete." In: CONCREEP 10, International Conference on Mechanics and Physics of Creep, Shrinkage and Durability of Concrete and Concrete Structures, Vienna 21-23 Spetember 2015, ASCE, 1187-1193.

Tasevski, D., Fernández Ruiz, M. and Muttoni, A., (2016). "Behaviour of concrete in compression and 
shear under varying strain rates: from rapid to longterm actions." In: Proceedings of the 11th fib International PhD Symposium in Civil Engineering, Tokyo 29-31August 2016, 881-886.

Troxell, G. E., Raphael, J. M. and Davis, R. E., (1958).

"Long-time creep and shrinkage tests of plain and reinforced concrete." ASTM Proceedings, 58, 11011120.

USSR, Ministry of Transport Construction, (1987). "Guidelines for calculation of stress state of reinforced concrete structures for transport construction with the account of creep and shrinkage of concrete." (in Russian: "Методические Рекомендации по Расчету Напряженного Состояния Железобетонных Конструкций Транспортных Сооружений с Учетом Ползучести и Усадки Бетона."). Ed. Hashachi, D., Moscow, Soviet Union.
Wang, Y., Zhou, N., Chang, F. and Hao, S., (2015). "Brittle creep failure, critical behavior, and time-tofailure prediction of concrete under uniaxial compression." Advances in Materials Science and Engineering, September 2015, 1-8.

Wittmann, F. H. and Zaitsev, J., (1974). "Deformation and rupture process of porous construction materials under short-term and sustained load." (in German: "Verformung und Bruchvorgang poröser Baustoffe bei kurzzeitiger Belastung und Dauerlast."). Report. Deutscher Ausschuss für Stahlbeton, Vol. 232, Ed. Berlin: Wilhelm Ernst and Sohn, 67-145.

Zhaoxia, L., (1994). "Effective creep Poisson's ratio for damaged concrete." International Journal of Fracture, 66(2), 189-196.

Zhou, F. P., (1992). "Time-dependent crack growth and fracture in concrete." Thesis (PhD). LTH, Lund University. 132 p. 
Appendix 1: Instantaneous stress - strain curve

The instantaneous monotonic stress - strain curves used in this paper have been obtained based on the equation proposed in (Fernández Ruiz et al. 2007). This curve refers to the reference response of concrete, loaded in compression at a strain rate of $\dot{\varepsilon}=0.02 \% \mathrm{o}^{\circ} \mathrm{s}^{-1}$ (approximately 100 seconds to failure) and is written as follows:

$$
\sigma_{c}=\frac{E_{c} \cdot \varepsilon_{c}}{1+\left(\frac{\varepsilon_{c}}{\varepsilon_{r e f}}\right)^{\alpha}}
$$

with

$$
\varepsilon_{r e f}=\frac{\alpha \cdot f_{c}}{E_{c} \cdot(\alpha-1)^{\left(1-\frac{1}{\alpha}\right)}}
$$

and

$$
\alpha=0.5+\frac{f_{c}[\mathrm{MPa}]}{25}+\frac{\left(f_{c}[\mathrm{MPa}]\right)^{2}}{1500}
$$

where the denominator in the second term of the $\alpha$ coefficient has been changed to 25 (original value was 20 (Fernández Ruiz et al. 2007)) in order to better approach the tested concrete behaviour (refer to Fig. A1).

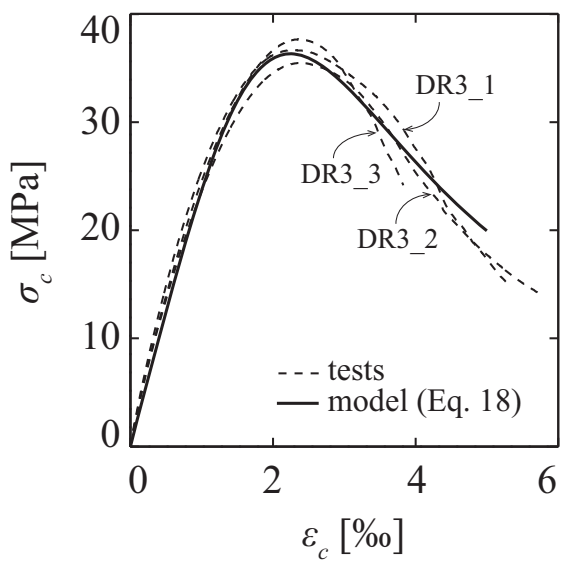

Fig. A1 Comparison between the instantaneous stressstrain curves from reference tests and the calculated one with Eq. (18).

\section{Notation}

$\underline{\text { Variables }}$

$E_{c} \quad$ modulus of elasticity of concrete

$f_{c}$ uniaxial compressive strength of concrete [MPa]

$f_{c, \text { ref }}\left(t_{0}\right)$ reference compressive strength obtained at a strain rate of $0.02 \%{ }^{\circ} \cdot \mathrm{s}^{-1}$ and at an age $t_{0}[\mathrm{MPa}]$

$f_{c, 28}$ reference compressive strength obtained at an age of 28 days [MPa]

$f_{c, \Delta t} \quad$ compressive stress at failure for a given longterm loading pattern $[\mathrm{MPa}]$

time

$t_{0} \quad$ concrete age at loading [days]

$t_{s} \quad$ concrete age at the beginning of drying [days]

$\Delta t \quad$ time under sustained stress for a constant stress level test or time after beginning of a strain or stress rate test (in the case of rapid initial loading, time after the initial loading ramp)

$\alpha$ parameter for instantaneous stress-strain model

$V \quad$ parameter characterizing tertiary creep

$\dot{\varepsilon} \quad$ strain rate

$\varepsilon_{c} \quad$ concrete strain

$\varepsilon_{c 0} \quad$ instantaneous pre-peak strain

$\varepsilon_{c, \text { trans }}$ transverse strain

$\varepsilon_{c, \text { long }} \quad$ longitudinal strain

$\eta \quad$ affinity coefficient

$v \quad$ Poisson's ratio

$\dot{\sigma} \quad$ stress rate

$\sigma_{c} \quad$ concrete stress

$\varphi \quad$ creep coefficient

\section{$\underline{\text { Indexes }}$}

av available

$c \quad$ concrete

calc calculated

$c c, 1$ primary creep

$c c, 2$ secondary creep

$c c, 3$ tertiary creep

cs shrinkage

eff effective

in inelastic

init initial

lin linear

nl nonlinear

test value from experimental result

tot total

$\tau \quad$ time-related 